\title{
Optics in Russia's Space Science Program
}

Yury Dobrolenskiy, Oleg Korablev

IKI - Space Research Institute of Russian Academy of Sciences 


\section{CURRENT RESEARCH}

In course

Mars Odyssey (HEND)

INTEGRAL (launch, 25\% obs. time) Mars Express ( 3 instruments)

LRO (LEND)

Curiosity (DAN)

RADIOASTRON

The most recent

Lomonosov (Moscow University)

ExoMars TGO (oper. Mar 2018)

\section{Upcoming}

Bepi Colombo (3 instruments)
2001

2002

2003

2009

2011

2011

2016

2016

20 Oct 2018
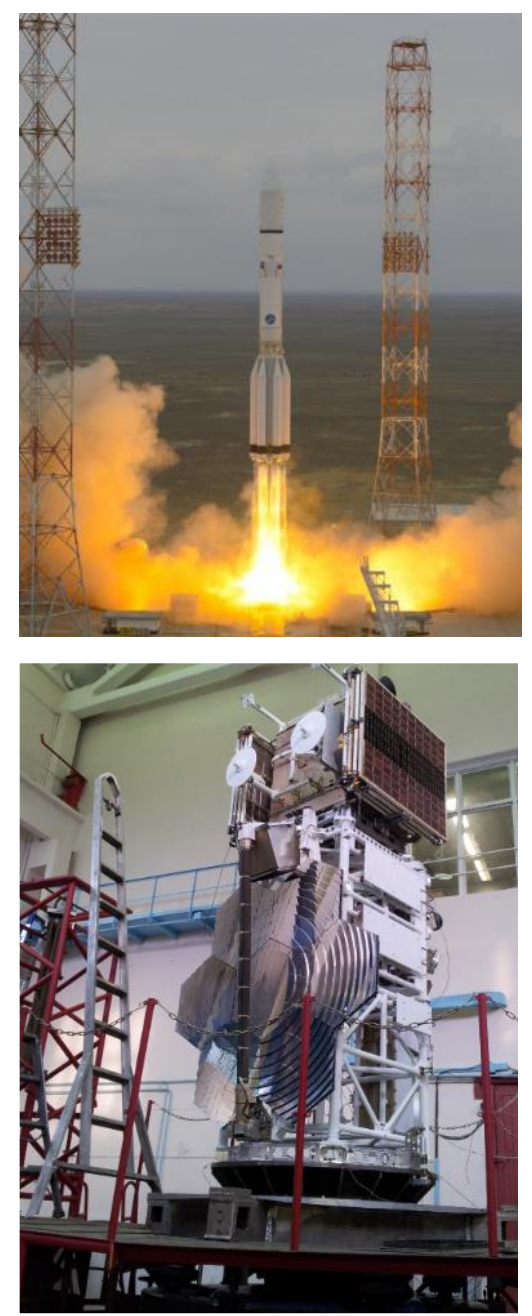


\section{Federal Space Programme, Fundamental Space Research 2016-2025}

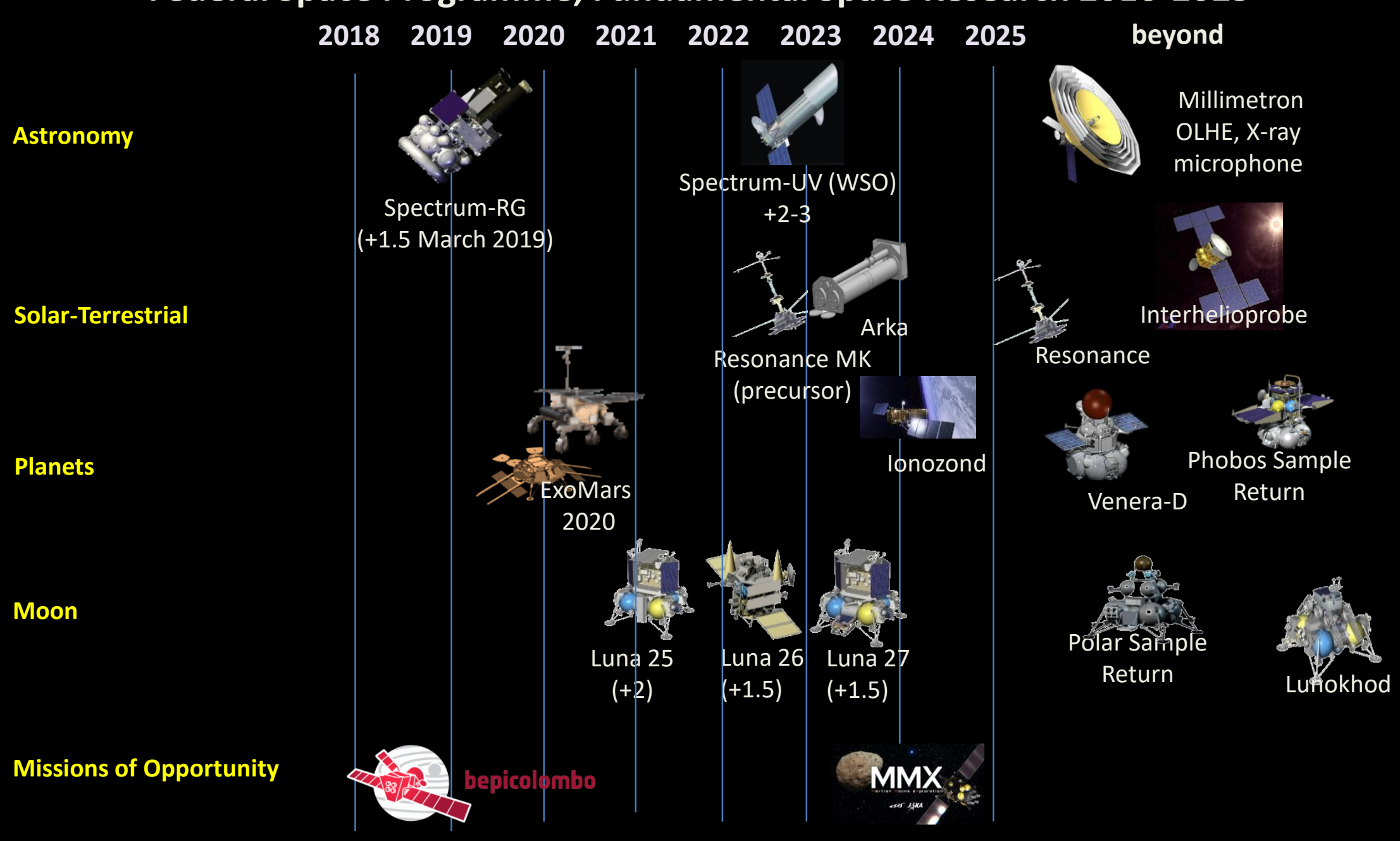




\section{Content}

- Mars missions (ExoMars 2016 and 2020)

- Mercury mission (BepiColombo)

- Lunar program

- Earth observations

- Telescopes for Astrophysics

- Example of the project beyond 2025 (Venera-D) 
The 2016 mission consists of a Trace Gas Orbiter (TGO) with four science instruments. It also included an EDL Demonstrator Module (EDM=Schiaparelli). Launched 14.03.2016, in orbit since 19.10.2016, aerobraking completed $\sim 10.03 .2018$

> The 2020 mission consists of a Carrier Module (CM) and a Descent Module (DM) with a Rover and a stationary Landing Platform
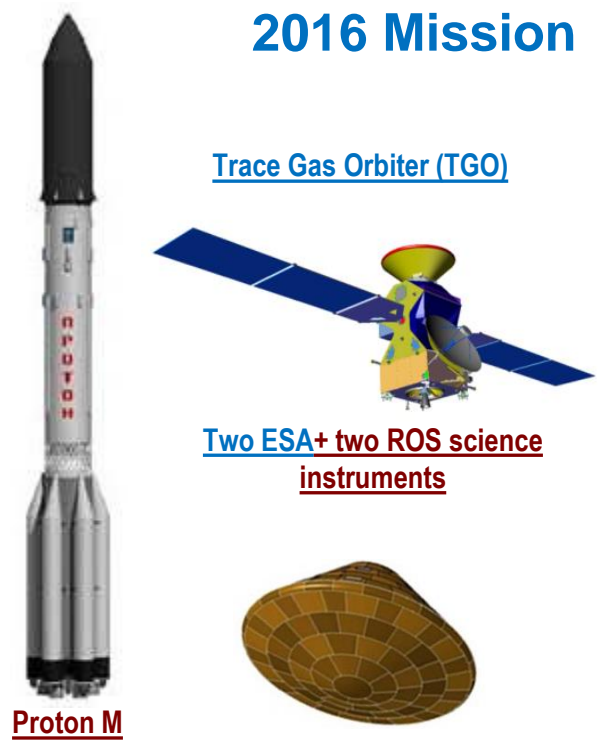

Two ESA+ two ROS science instruments

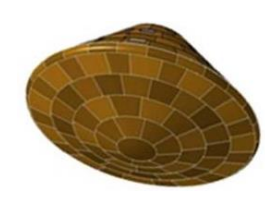

Schiaparelli EDL Demonstrator Module (EDM)

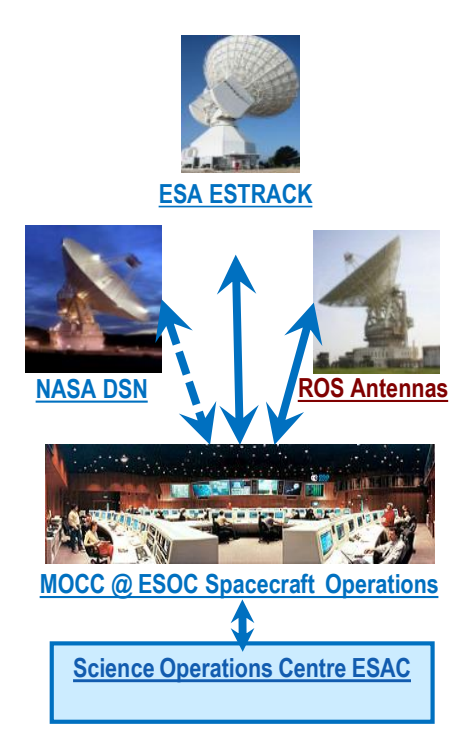

Science Archive Back-up Centre IKI

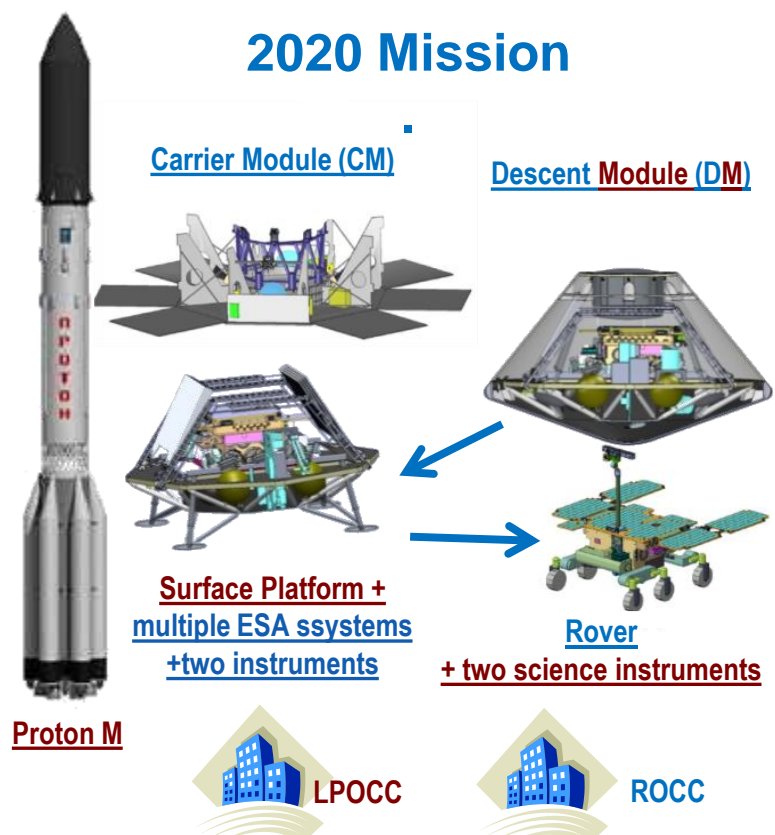


ecosa

European Space Agency

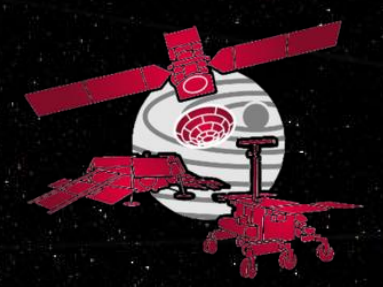

(4) POCKOCMOC

$\rightarrow \quad 0$

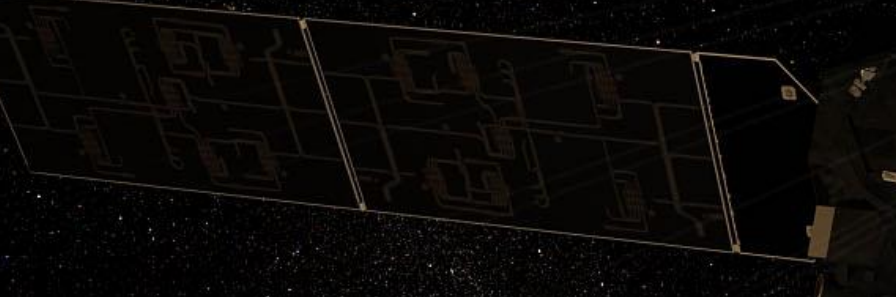

.

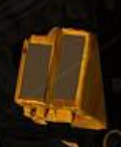

a

C.

\section{ExoMars Trace Gas Orbiter}




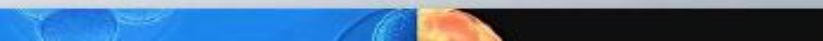

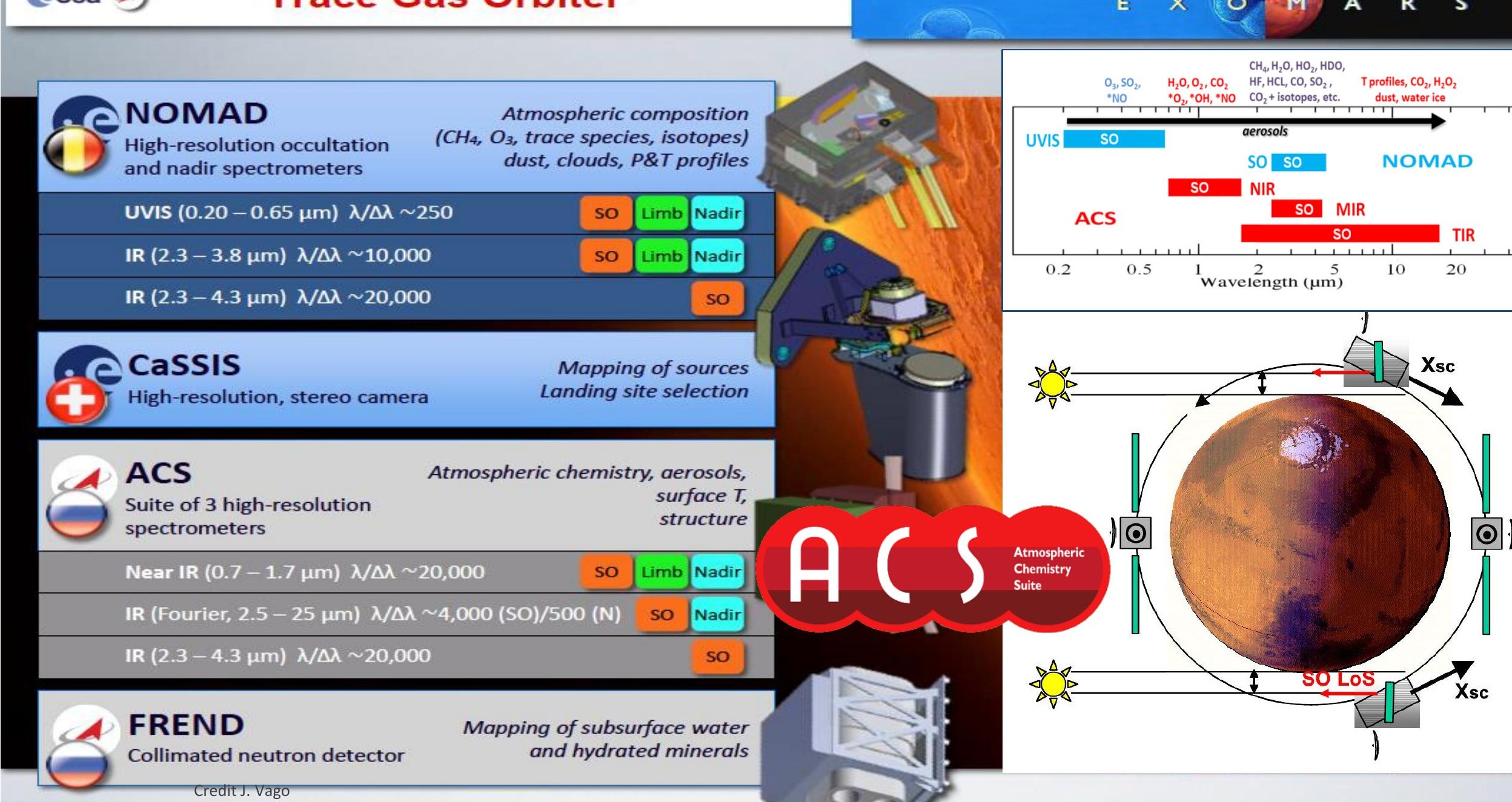




\section{BE (main electronics)}

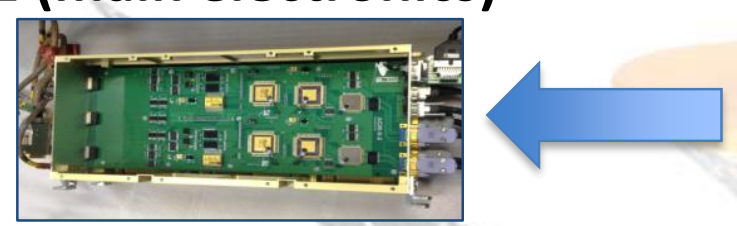

electrical interface of the ACS to the spacecraft

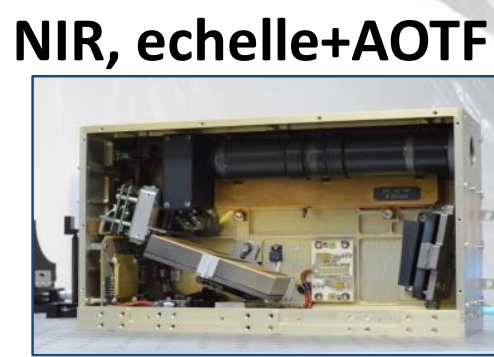

- Spectral range 0.73-1.6 $\mu \mathrm{m}$

- $\lambda / \Delta \lambda \sim 25000$

- Nadir and Solar Occultation

- FOV: $2^{\circ} \times 0.02^{\circ}$ nadir, $0.3^{\circ} \times 0.02^{\circ}$

occultation

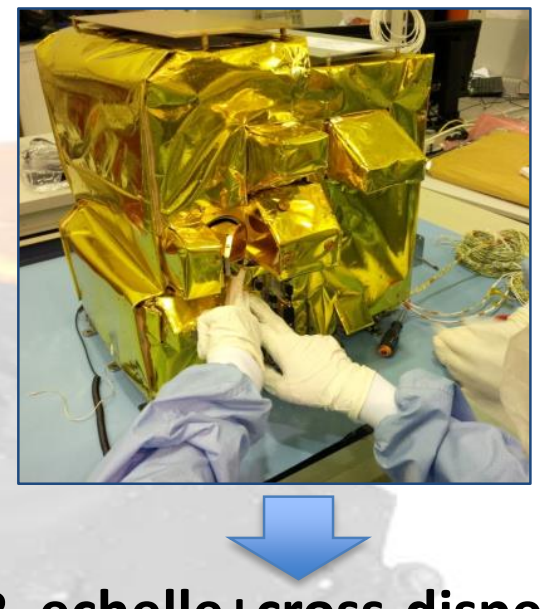

MIR, echelle+cross-dispersion

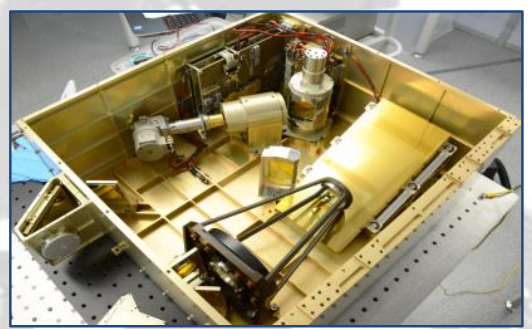

- Spectral range $2.3-4.2 \mu \mathrm{m}$

- $\lambda / \Delta \lambda \sim 50000$ (Solar Occultation only)

- FOV: $0.23^{\circ} \times 0.02^{\circ}$
ACS - Atmospheric Chemistry Suite: three spectrometers

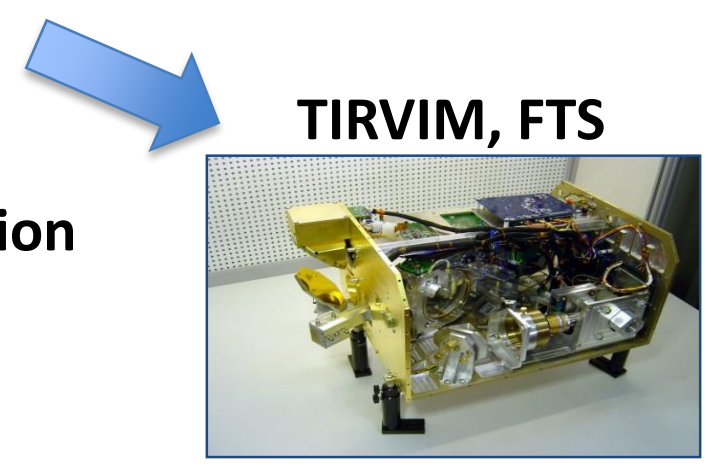

-Spectral range $1.7-17 \mu \mathrm{m}\left(580-5800 \mathrm{~cm}^{-1}\right.$ - $\Delta v^{\sim} 0.13 \mathrm{~cm}^{-1}$ (Sun), $0.8 \mathrm{~cm}^{-1}$ (Mars)

- Nadir and Solar Occultation

- FOV: $\varnothing 2.5^{\circ}$

Korablev, O. et al. Space Sci. Rev. 214:7, doi:10.1007/s11214-11017-10437-11216 (2018) 
ACS-Near Infra-Red (NIR) 0.7-1.7 $\mu$; $\lambda / \Delta \lambda \sim 20000$
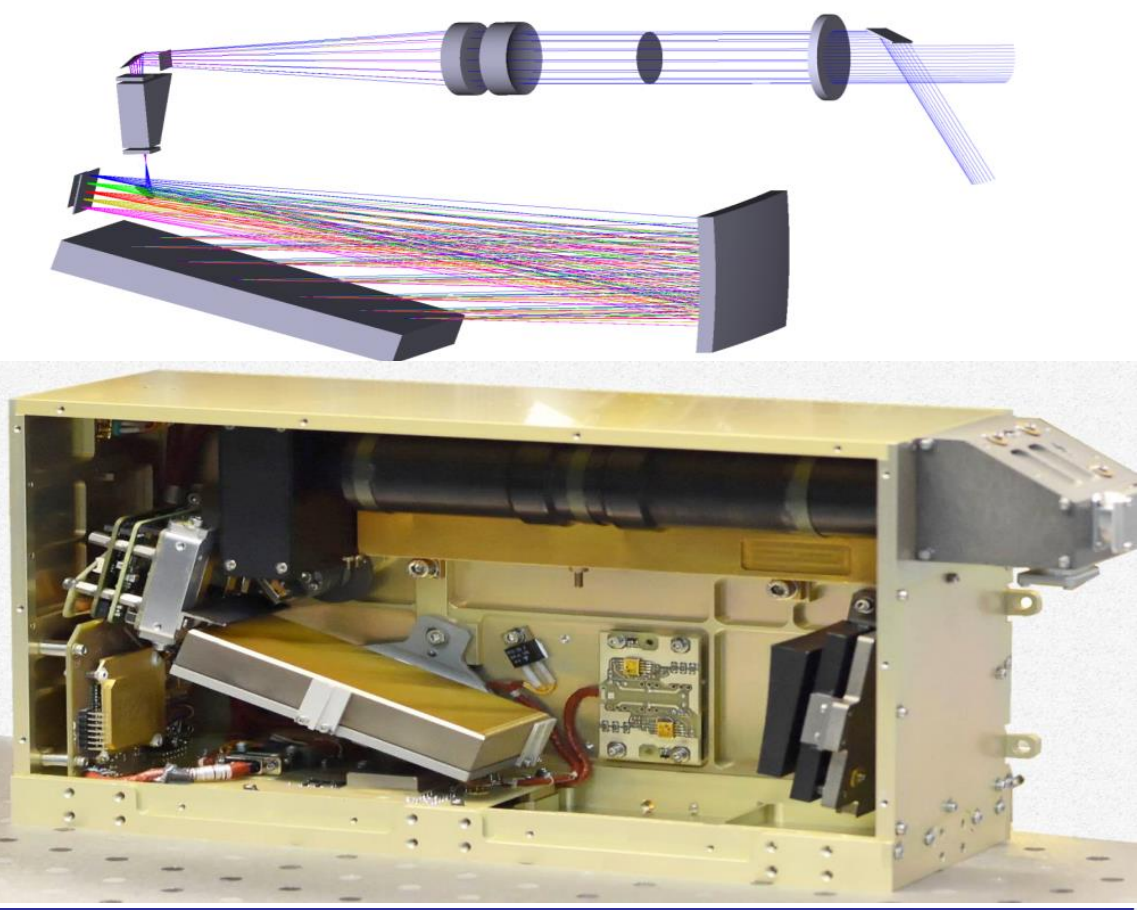

- Continuation of SPICAMIR/Mex

- The instrument principle of SOIR/VEX (Echelle+AOTF)

- Extended spectral range w.r.t. SPICAM (starts at $0.7 \mu \mathrm{m}$ )

- 10-fold better spectral resolution

- Solar Occultation

- Nadir 


\section{ACS NIR first data}

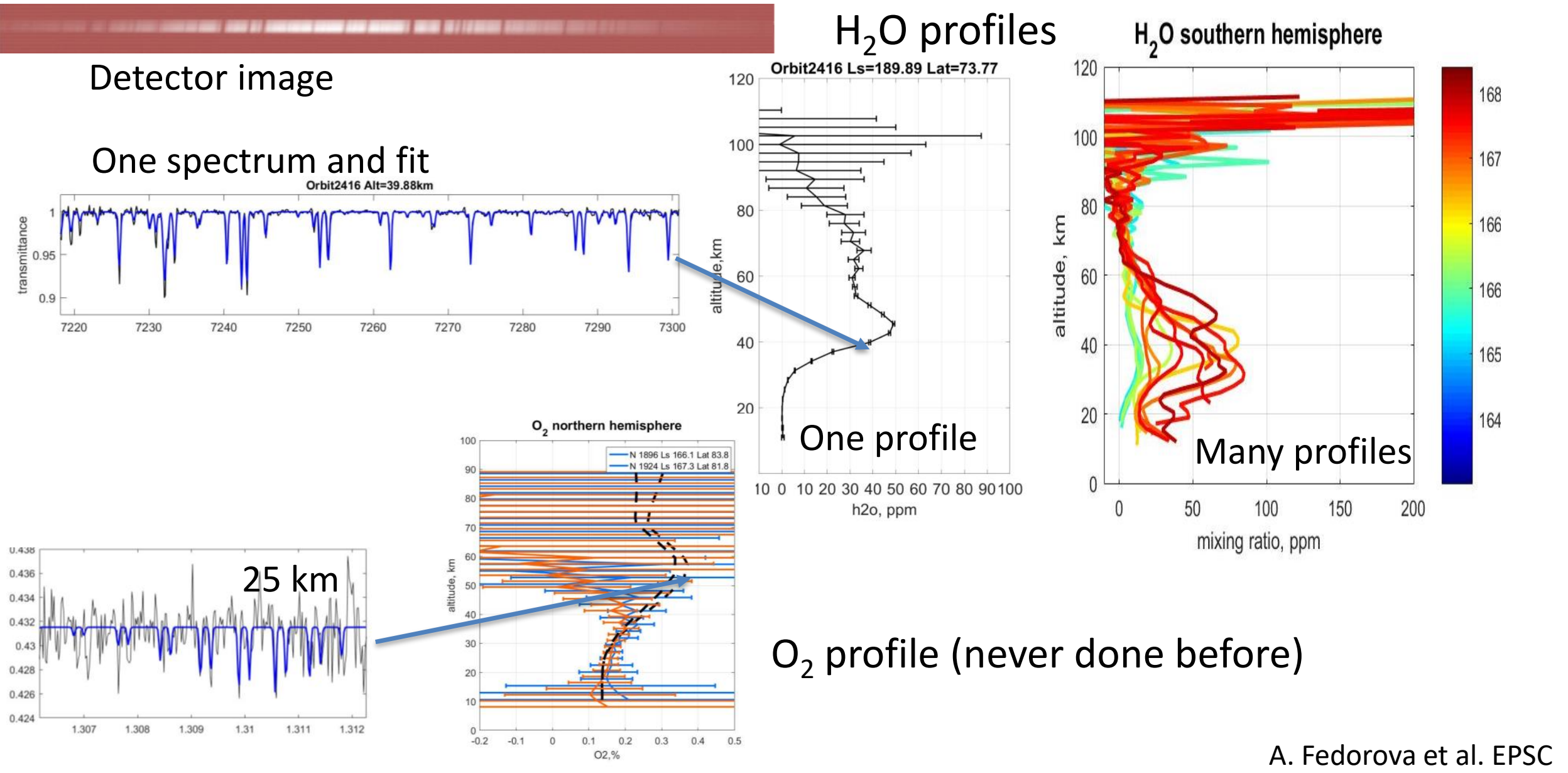




\section{ACS TIRVIM products}

Nadir: Spectra

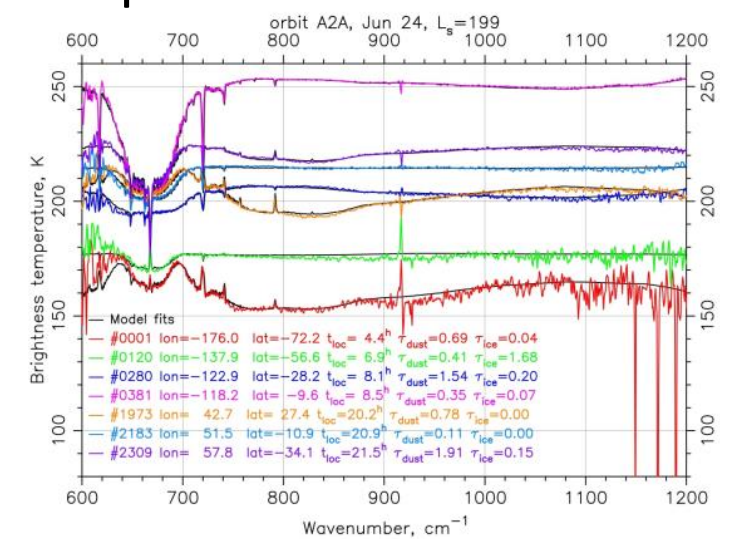

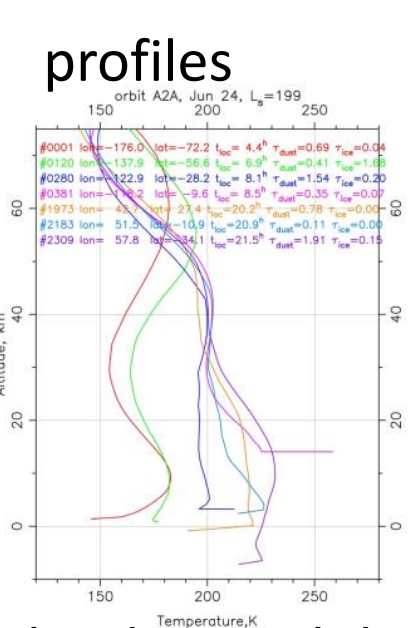

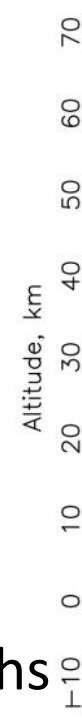

S:

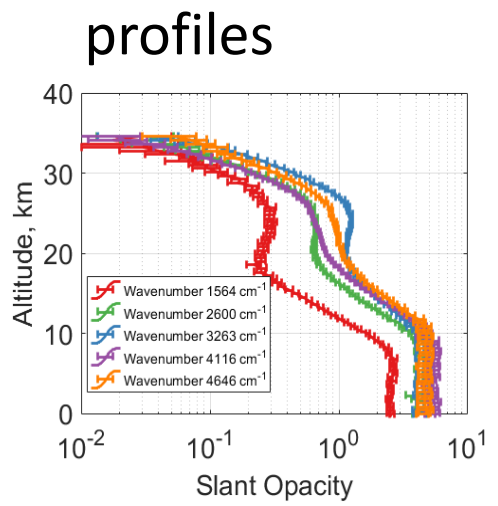

T-fields

$L s=199^{\circ}$

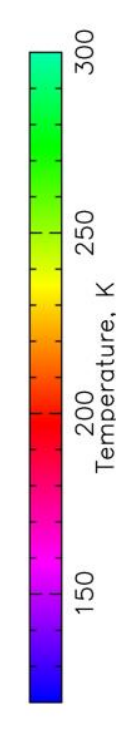

Occultation : Spectra

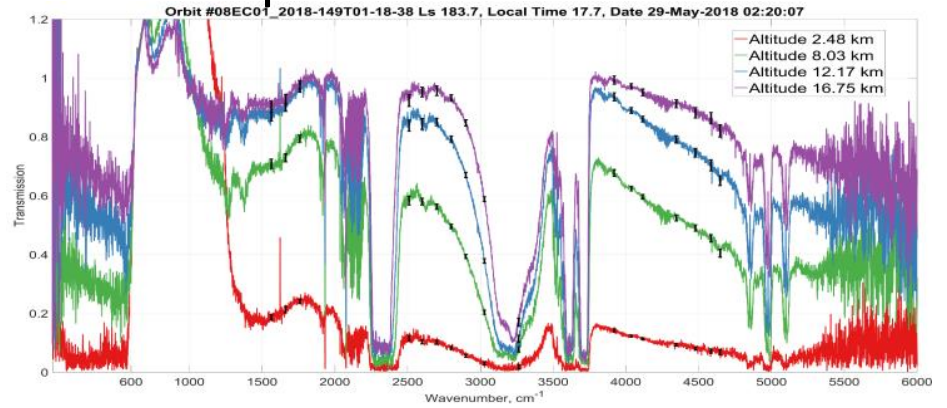

N. Ignatiev et al M. Luginin et al

EPSC

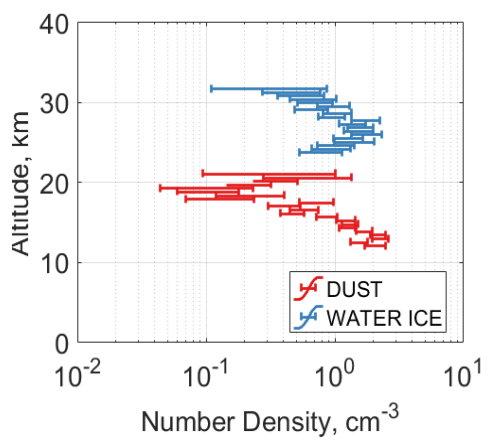

T surf

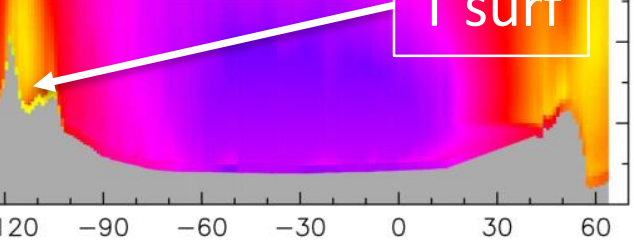

aerosols ${ }^{\text {Longitude }}$ 


\section{ACS-Middle-IR (MIR)}

Echelle crossed dispersion

2.3-4.2 $\mu \mathrm{m} ; \lambda / \Delta \lambda \sim 50000$

- Solar occultation only

- Best spectral resolution and SNR

- No diffraction order overlapping

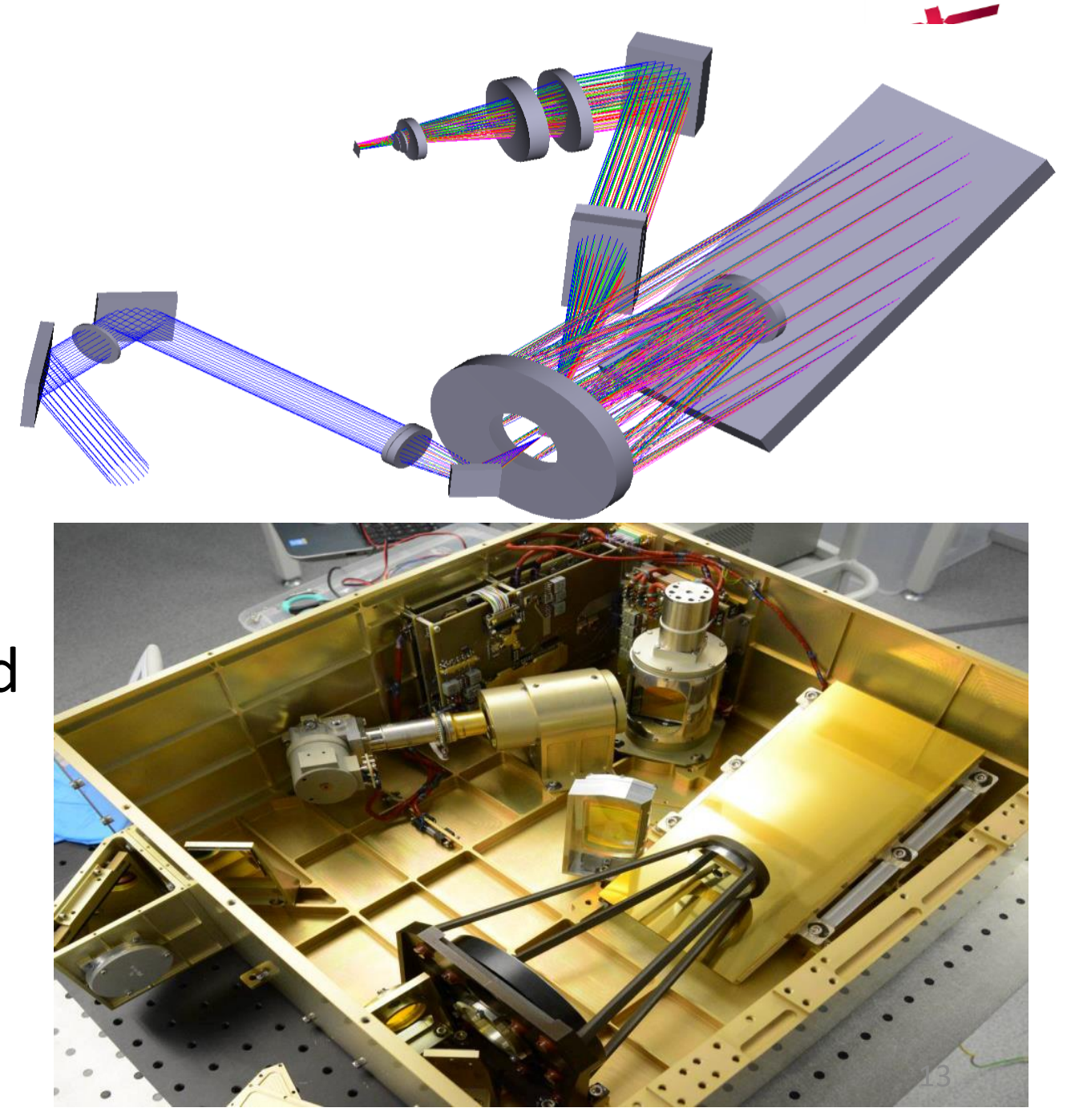




\section{Detector image}

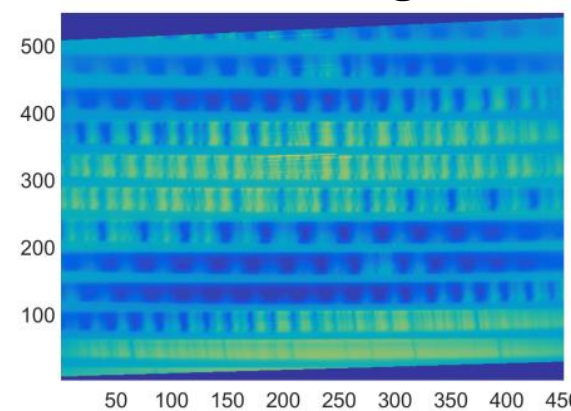

One spectrum and fit

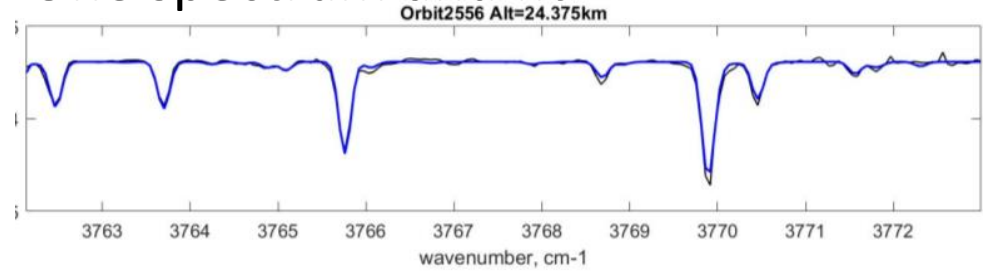

$\begin{array}{lllllllll}50 & 100 & 150 & 200 & 250 & 300 & 350 & 400 & 450\end{array}$

Orbit 2556, Position 4, $2.7 \mu \mathrm{m}$

Transmittance at $30 \mathrm{~km}$

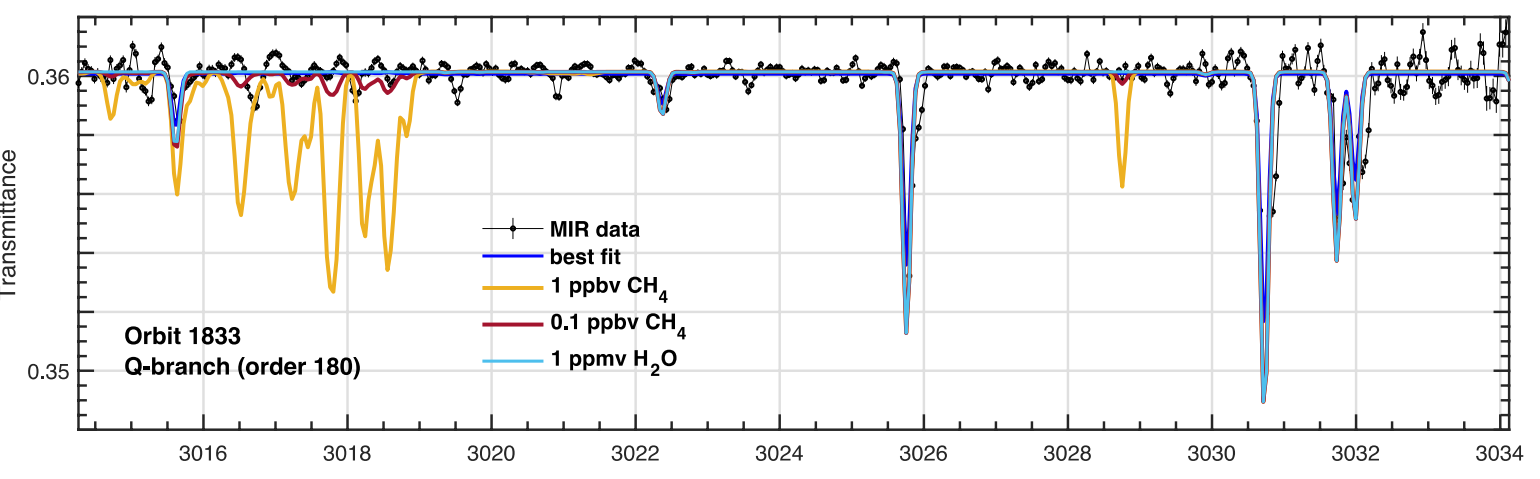

A spectrum in the $\mathrm{CH}_{4}$ range

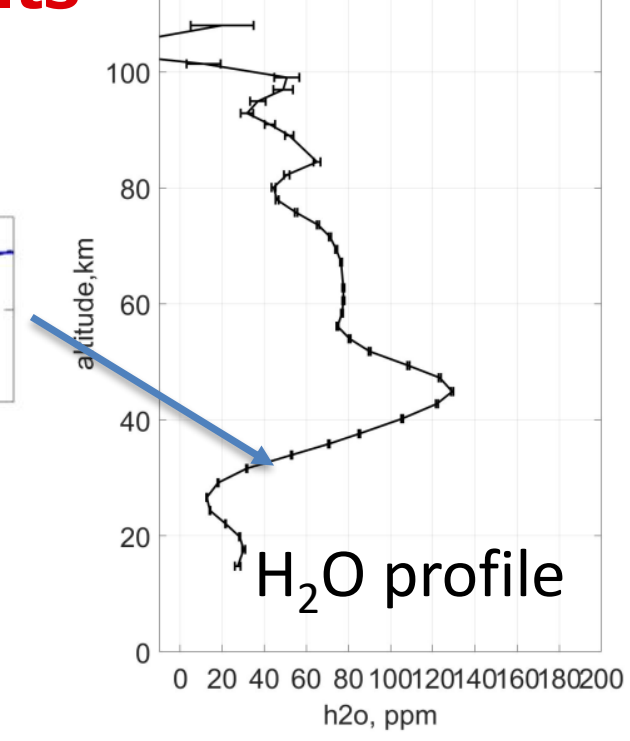

- Full MIR pipeline is not finished yet

- SNR for the out-of-the-atmosphere spectra in the central part of the detector reaches 5000-6000 for a single pixel and is $\geq 10000$ after averaging

- Confirmed spectral resolving power $R \approx 30000$ 


\section{ExoMars 2020:}

\section{Rover and Landing Platform}
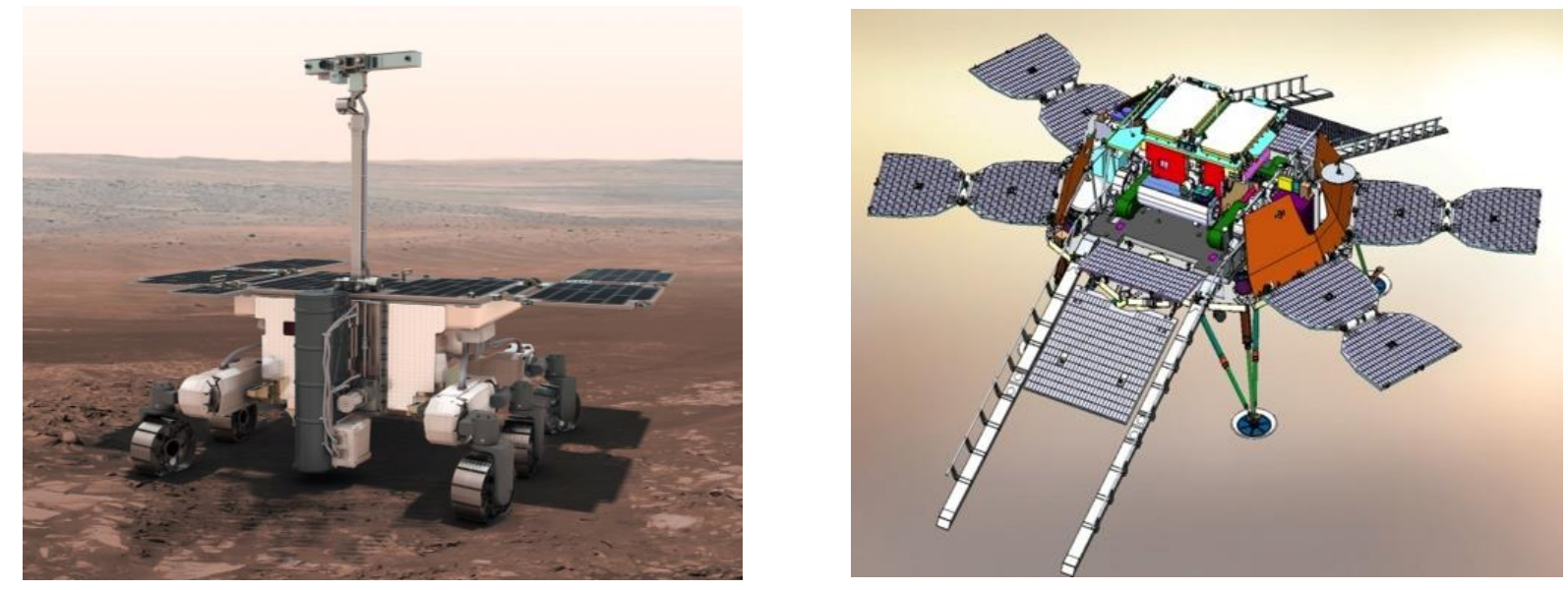


\begin{tabular}{|c|c|c|}
\hline & $\begin{array}{l}\text { PanCam } \\
\text { Wide-angle stereo camera pair } \\
\text { High-resolution camera }\end{array}$ & $\begin{array}{r}\text { Geological context } \\
\text { Rover traverse planning } \\
\text { Atmospheric studies }\end{array}$ \\
\hline \multicolumn{3}{|c|}{ WAC: $35^{\circ}$ FOV, HRC: $5^{\circ}$ FOV } \\
\hline & $\begin{array}{l}\text { ISEM } \\
\text { IR spectrometer on mast }\end{array}$ & $\begin{array}{r}\text { Bulk mineralogy of outcrops } \\
\text { Target selection }\end{array}$ \\
\hline \multicolumn{3}{|c|}{$\lambda=1.15-3.3 \mu \mathrm{m}, 1^{\circ} \mathrm{FOV}$} \\
\hline & $\begin{array}{l}\text { CLUP| } \\
\text { Close-up imager }\end{array}$ & $\begin{array}{r}\text { gical deposition environment } \\
\text { Microtexture of rocks } \\
\text { Morphological biomarkers }\end{array}$ \\
\hline & \multicolumn{2}{|c|}{$20-\mu \mathrm{m}$ resolution at $50-\mathrm{cm}$ distance, focus: $20 \mathrm{~cm}$ to $\infty$} \\
\hline & $\begin{array}{l}\text { WISDOM } \\
\text { Ground-penetrating radar }\end{array}$ & $\begin{array}{r}\text { Mapping of subsurface } \\
\text { stratigraphy }\end{array}$ \\
\hline \multicolumn{3}{|c|}{$3-5-\mathrm{m}$ penetration, $2-\mathrm{cm}$ resolution } \\
\hline & $\begin{array}{l}\text { ADRON } \\
\text { Passive neutron detector }\end{array}$ & $\begin{array}{r}\text { Mapping of subsurface water } \\
\text { and hydrated minerals }\end{array}$ \\
\hline & \multicolumn{2}{|c|}{$\begin{array}{l}\text { Drill + Ma__MISS In-situ mineralogy information } \\
\text { IR borehole spectrometer }\end{array}$} \\
\hline & $\lambda=0.4-2.2 \mu \mathrm{m}$ & \\
\hline
\end{tabular}

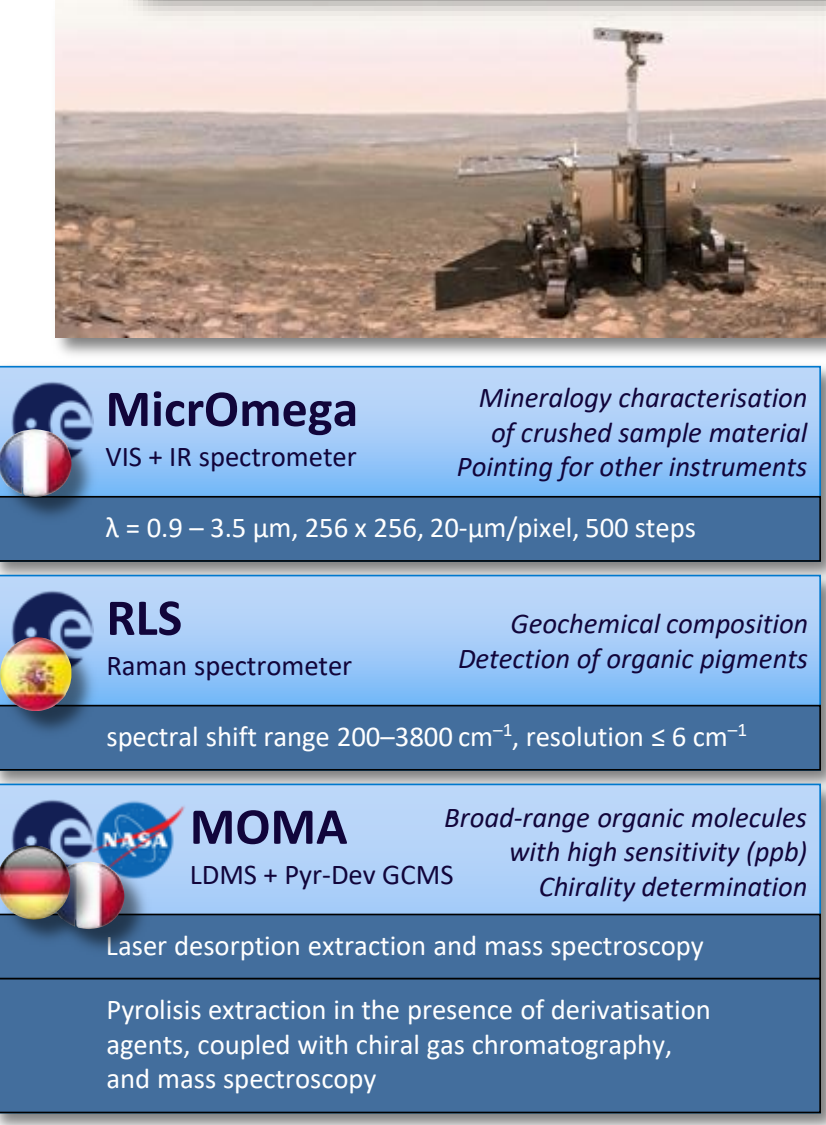




\section{ISEM (Infrared Spectrometer for ExoMars)}

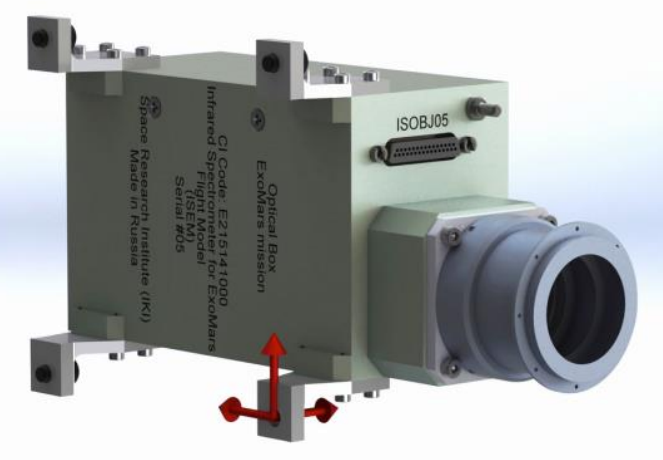

Optical Box (OB) ISEM

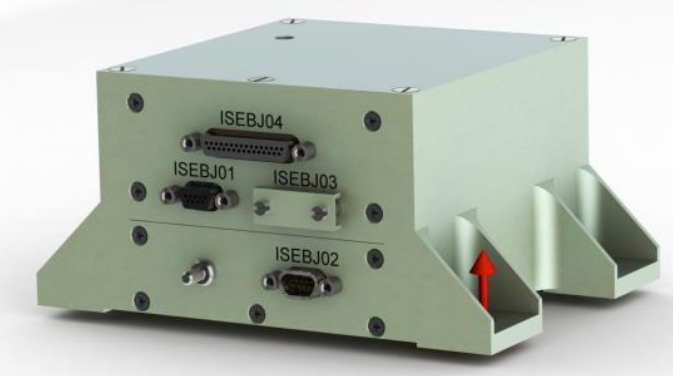

Electronic Box (EB) ISEM

O. Korablev (PI), Y. Dobrolenskiy (IM) and the ISEM Team IKI - Space Research Institute, Moscow Vernadsky Institute of Geochemistry and Analytical Chemistry, Moscow NII MicroPriborov Guskova - Zelenograd

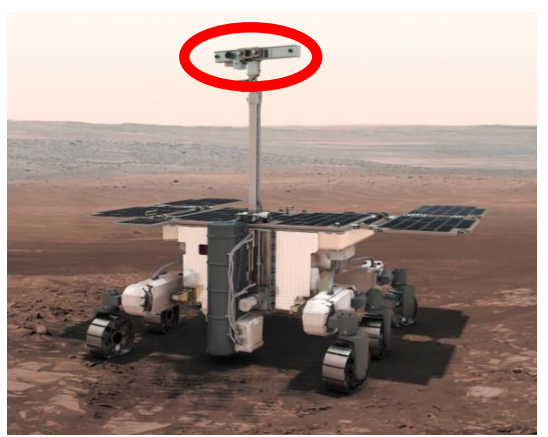




\section{Instrument accommodation. Flight model delivered in August 2018!}
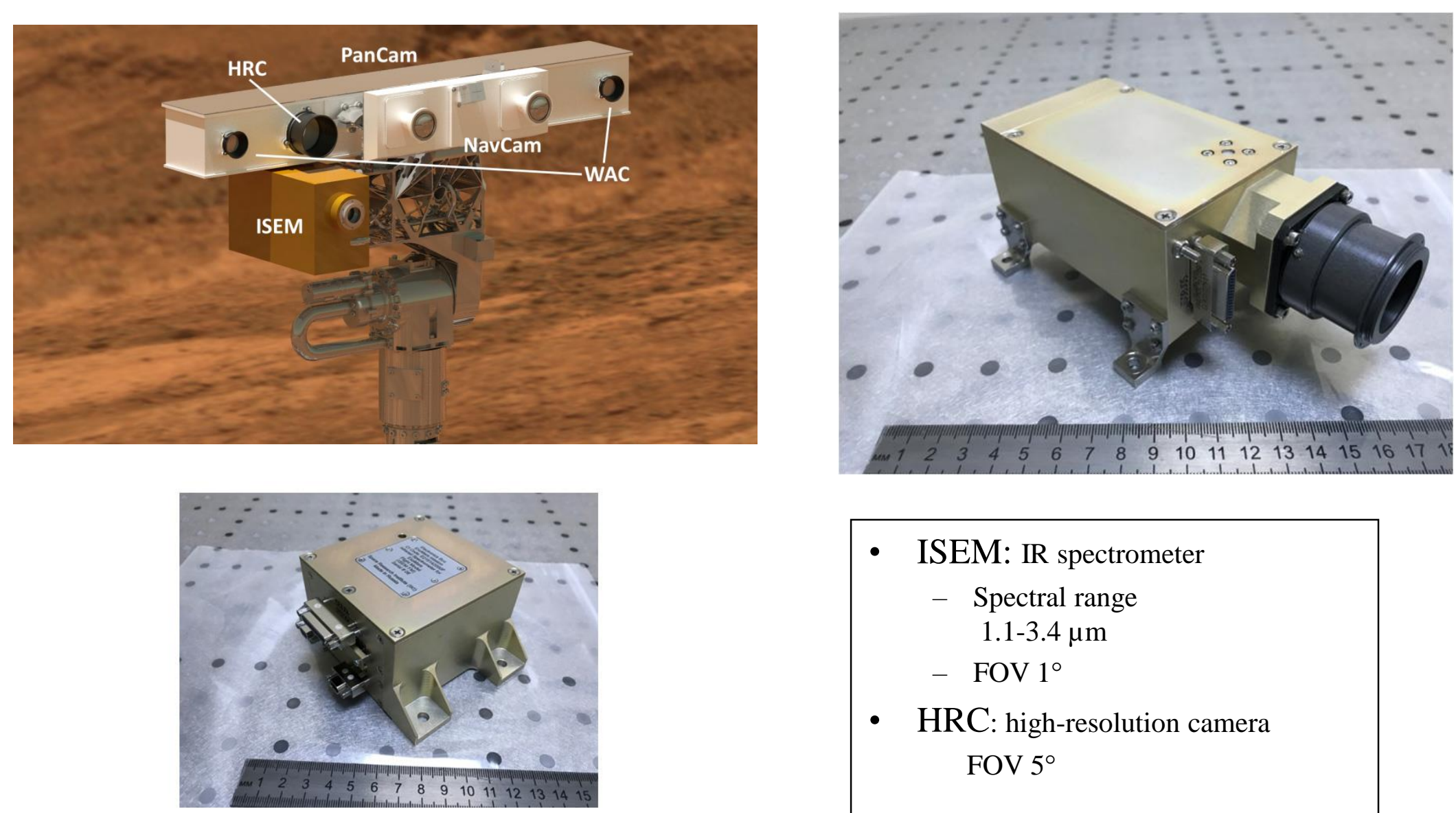

- ISEM: IR spectrometer

- Spectral range 1.1-3.4 $\mu \mathrm{m}$

- FOV $1^{\circ}$

- HRC: high-resolution camera FOV $5^{\circ}$ 


\section{ISEM OB: 3D model and optical scheme}
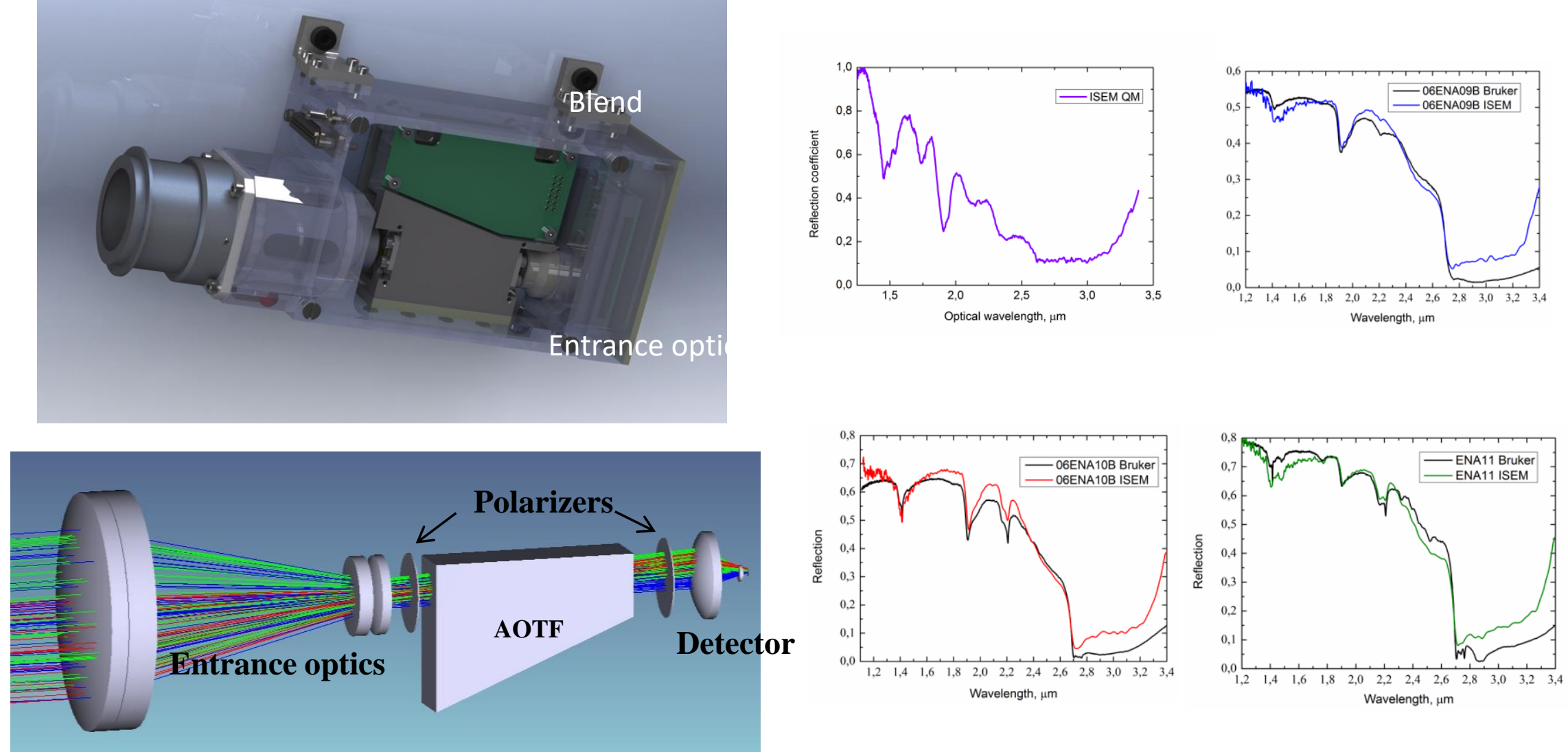


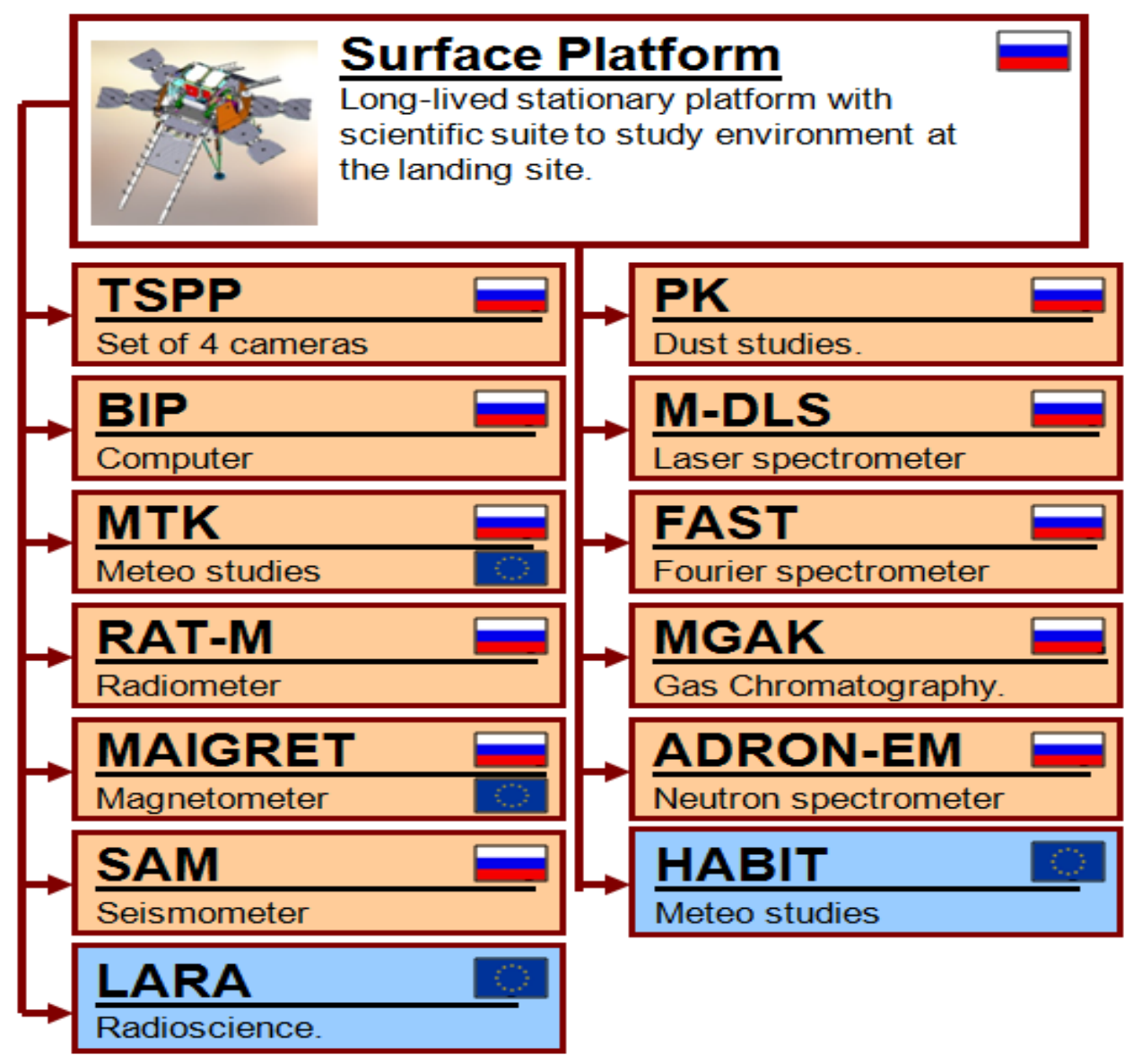




\section{TSPP}

Television system for the ExoMars surface platform

Scientific and applied objectives:

- Characterize the landing site environment;

- $360^{\circ}$ degree panoramic still and/or video survey of surface and atmosphere processes;

- Spectral radiance measurements;

- Imaging of surface, horizon and landing site during the spacecraft descent;

- ExoMars rover exit visual control;

- Support for other experiments onboard the surface platform.

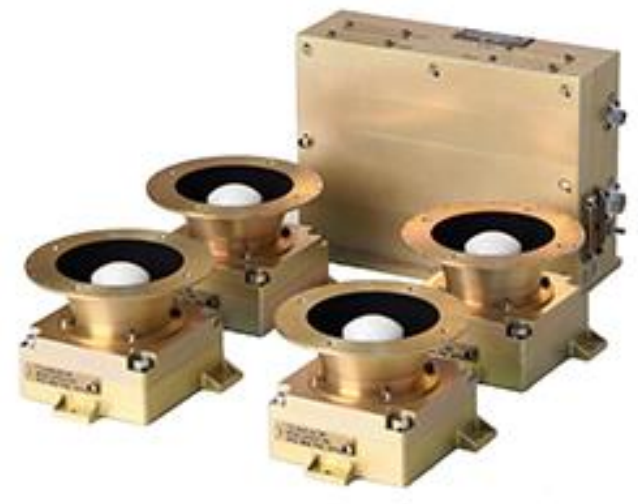

Principal functions:

- Acquisition of Martian surface and atmosphere static and/or sequential images in visible spectral range;

- Permanent storage of imagery data in non-volatile mass memory;

- Image compression and transfer with auxiliary data to BIP/radio channel. 


\section{TSPP - Camera head technical performance}

\begin{tabular}{|c|c|}
\hline Parameter & Value \\
\hline No of heads & 4 \\
\hline Angular FOV & $115^{\circ} \times 115^{\circ}$ each \\
\hline Sensor size & $11,264 \mathrm{~mm} \times 11,264 \mathrm{~mm}$ \\
\hline Number of active pixels & $2048 \times 2048$ \\
\hline Aperture & $f: 8$ \\
\hline Angular resolution & $1 \mathrm{mrad}$ \\
\hline Bit depth & $8 \mathrm{bpp}$ \\
\hline Color & RGB, NIR cut-off \\
\hline Frame rate, $\max$ & $1 \mathrm{fps} @ 2 \mathrm{k} \times 2 \mathrm{k}$ \\
\hline Single frame dynamic range & $60 \mathrm{~dB}$ \\
\hline Depth of field & $1 \mathrm{~m}$ to $\infty$ \\
\hline Mass & $0,4 \mathrm{~kg}$ \\
\hline Size & $79 \times 109 \times 97 \mathrm{~mm}$ \\
\hline Supply voltage & 5 VDC \\
\hline Power consumption & $1,8 \mathrm{~W}$ \\
\hline
\end{tabular}




\title{
M-DLS - Multichannel Diode Laser Spectrometer
}

\author{
Science \\ Continuous observations of chemical and isotopic \\ objectives \\ atmosphere composition near the surface during \\ platform's lifetime.
}

Prototype Luna-Resource, Phobos-Grunt.

Implementation High-resolution, highly sensitive tunable diode laser absorption spectroscopy (TDLAS) combined with optical path enhancement by integrated cavity output spectroscopy (ICOS).

Molecular absorption measurement at $2.6 \div 2.9 \mu \mathrm{m}$.

Search for diurnal, seasonal and sporadic variations of $\mathrm{H}_{2} \mathrm{O}, \mathrm{HDO}, \mathrm{H}_{2}{ }^{18} \mathrm{O}$; $\mathrm{CO}_{2},{ }^{13} \mathrm{CO}_{2}, \mathrm{CO}^{18} \mathrm{O}, \mathrm{CO}^{17} \mathrm{O}$.

Atmosphere gas sampling via MGAP instrument.

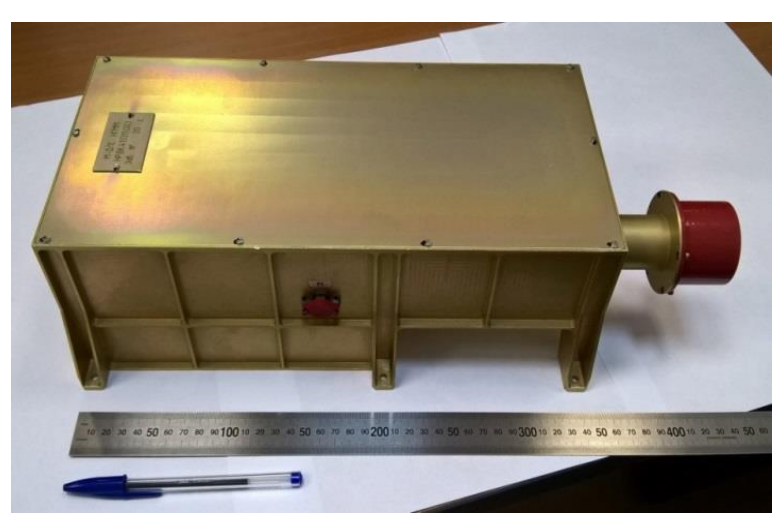

European contribution
GSMA/CNRS (France) - laboratory tests, instrument characterization, data treatment. 


\section{MEASUREMENT METHOD}

- In the M-DLS experiment, Martian atmosphere will be studied by optical measurements of molecular absorption spectrum of ambient gas sample, to be taken from close proximity of the stationery landing platform.

- High precision, sensitivity and flexibility of TDLAS are combined with advantages of ICOS, which is capable for radical optical path enhancement up to $\sim 10^{3}$, needed for fine measurements of weak absorption at low pressure of Martian atmosphere sample.

- $\mathrm{H}_{2} \mathrm{O}$ and $\mathrm{CO}_{2}$ molecular content and isotopic ratio variations will be retrieved from absorption spectra raw data, which should be send back to Earth and stored for on-ground processing and analysis.

- Gas sample will be sounded inside a compact analytical multi-path ICOS optical cell by highly monochromatic radiation of two tuneable DFB-lasers, emitting in the NIR range:

- at $2.65 \mu \mathrm{m}$ for $\mathrm{H}_{2} \mathrm{O}$, and $\mathrm{HDO}, \mathrm{HO}^{18} \mathrm{O}$;

- at $2.81 \mu \mathrm{m}$ for $\mathrm{CO}_{2}$, and ${ }^{13} \mathrm{CO}_{2}, \mathrm{CO}^{17} \mathrm{O}, \mathrm{CO}^{18} \mathrm{O}$.

- Measurements will be carried out sequentially within $\sim 1 \mathrm{~cm}^{-1}$ wide intervals, and with spectral resolution up to $\sim 10 \mathrm{MHz}\left(\sim 0.0003 \mathrm{~cm}^{-1}\right)$, resulting in accurate recording of molecular absorption line contours.

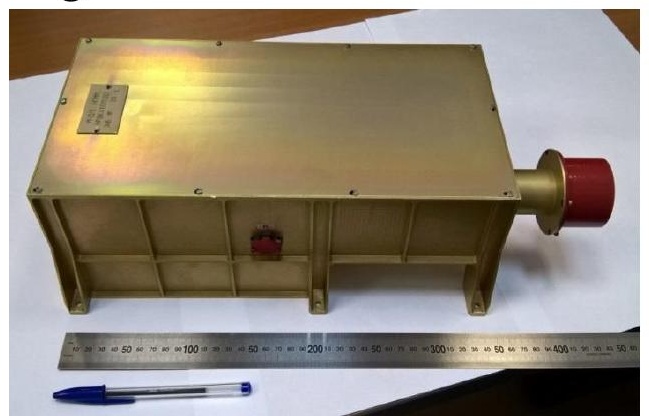




\title{
ODS (Optical Depth Sensor)
}

\author{
part of Meteo Suite (MTK)
}

- ODS is a lightweight instrument designed for measurements of dust optical depth and cloud altitude from the meteorological station deployed at the surface of Mars

- The sensor consists of 2 channels (red and blue) with broad field of view allowing the observation of scattered sunlight from sunrise to sunset, and of the sum of scattered and direct sunlight when the sun is passing within the field of view.
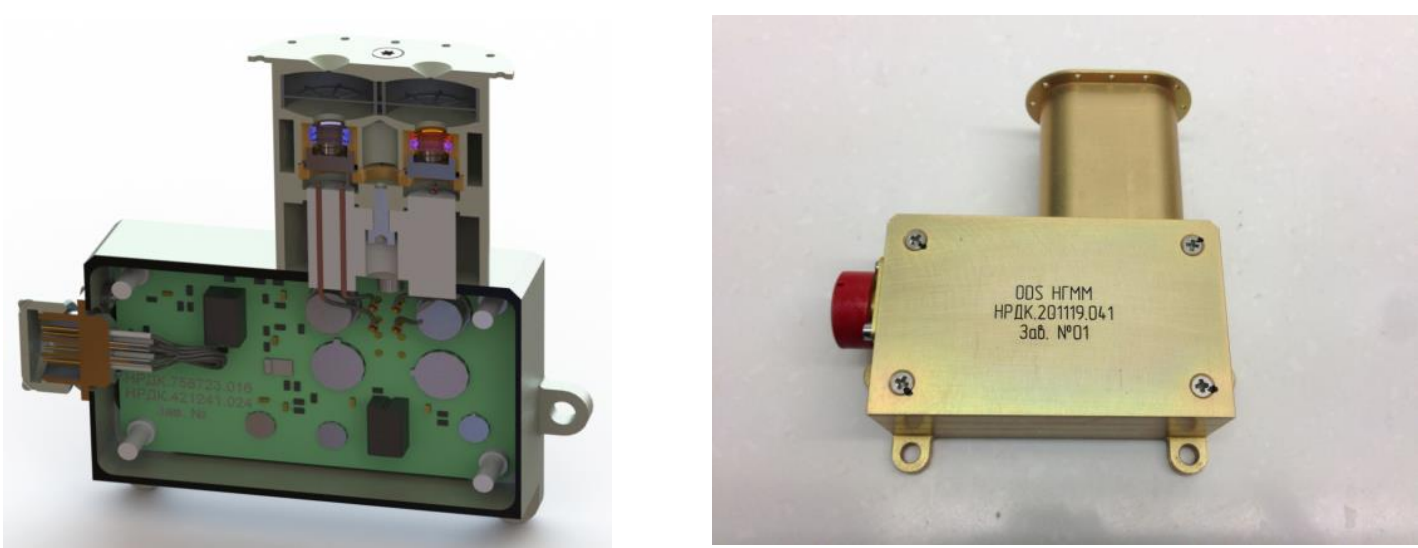


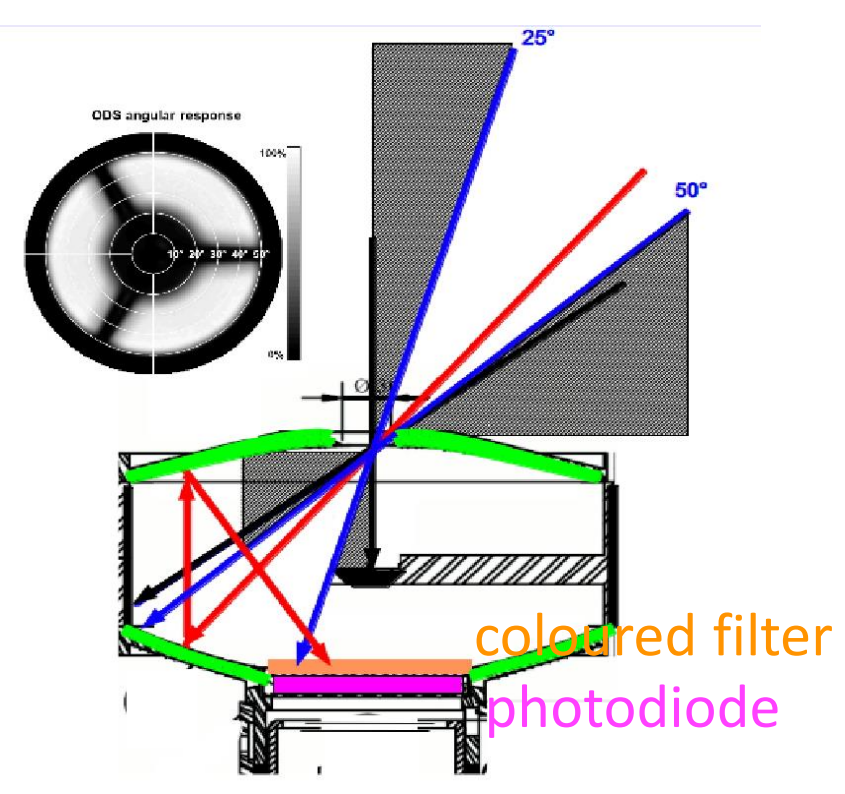

Scheme of the optical head. The field of view is annular. Only rays within a zenith angle between $25^{\circ}$ and $50^{\circ}$ pass through

\section{ODS Principle}

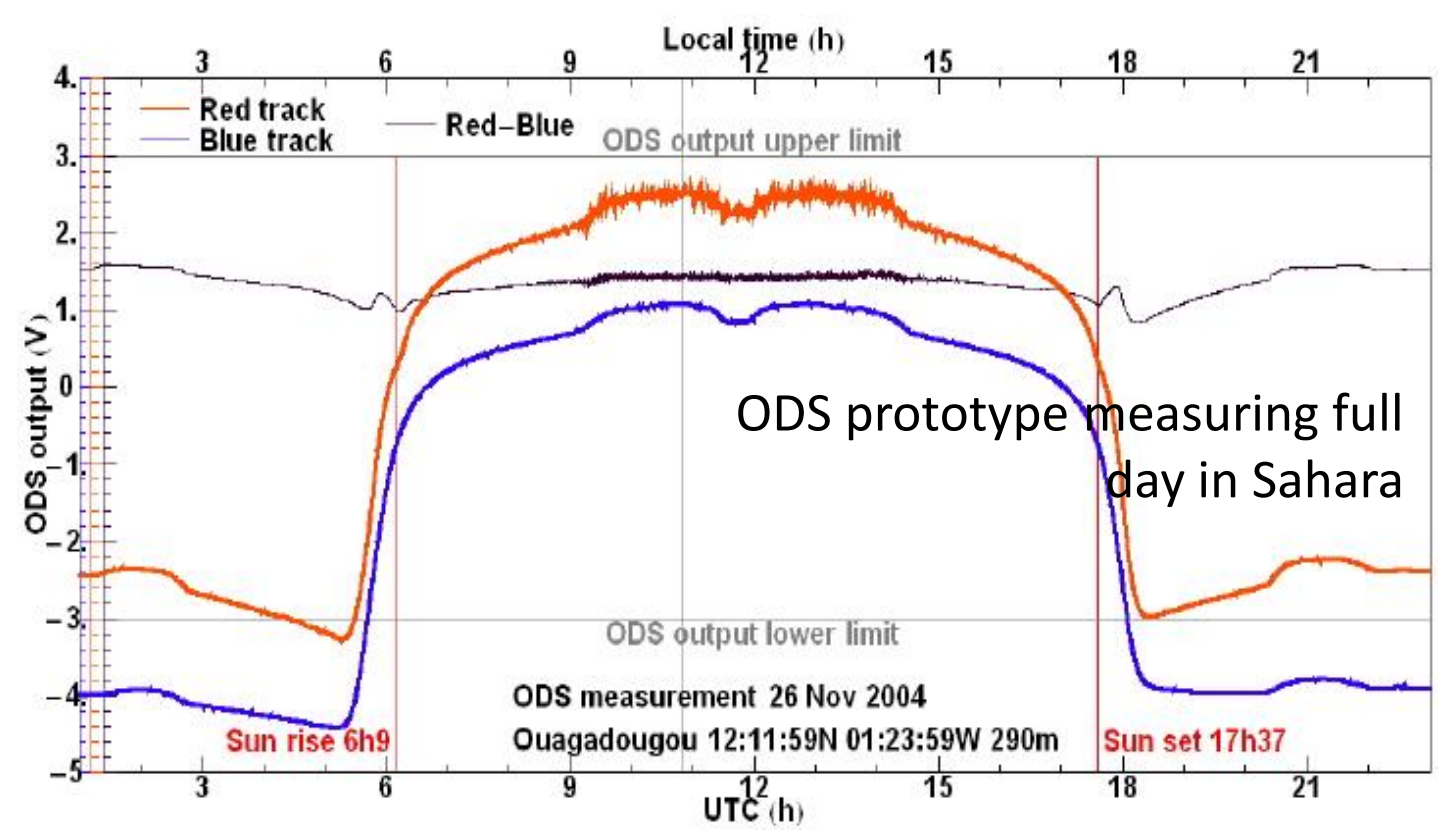

The aerosol optical depth is retrieved comparing the amplitude of the ratio between scattered-light only and direct sun plus scattered light, maximal in clear sky conditions and minimal at large optical depth 


\section{Content}

- Mars missions (ExoMars 2016 and 2020)

- Mercury mission (BepiColombo)

- Lunar program

- Earth observations

- Telescopes for Astrophysics

- Example of the project beyond 2025 (Venera-D) 


\section{Bepi Colombo: Russian contribution}

- Entrance optics and guiding system for UV-spectrometer PHEBUS (together with French and Japanese colleagues)

- Electron-optical system for PICAM (Planetary Ion Camera), part of SERENA complex (together with French and Austrian colleagues)

- Optical-mechanical unit for MSASI imager (together with Japanese colleagues) 
Bepi Colombo 2018: PHEBUS and MSASI
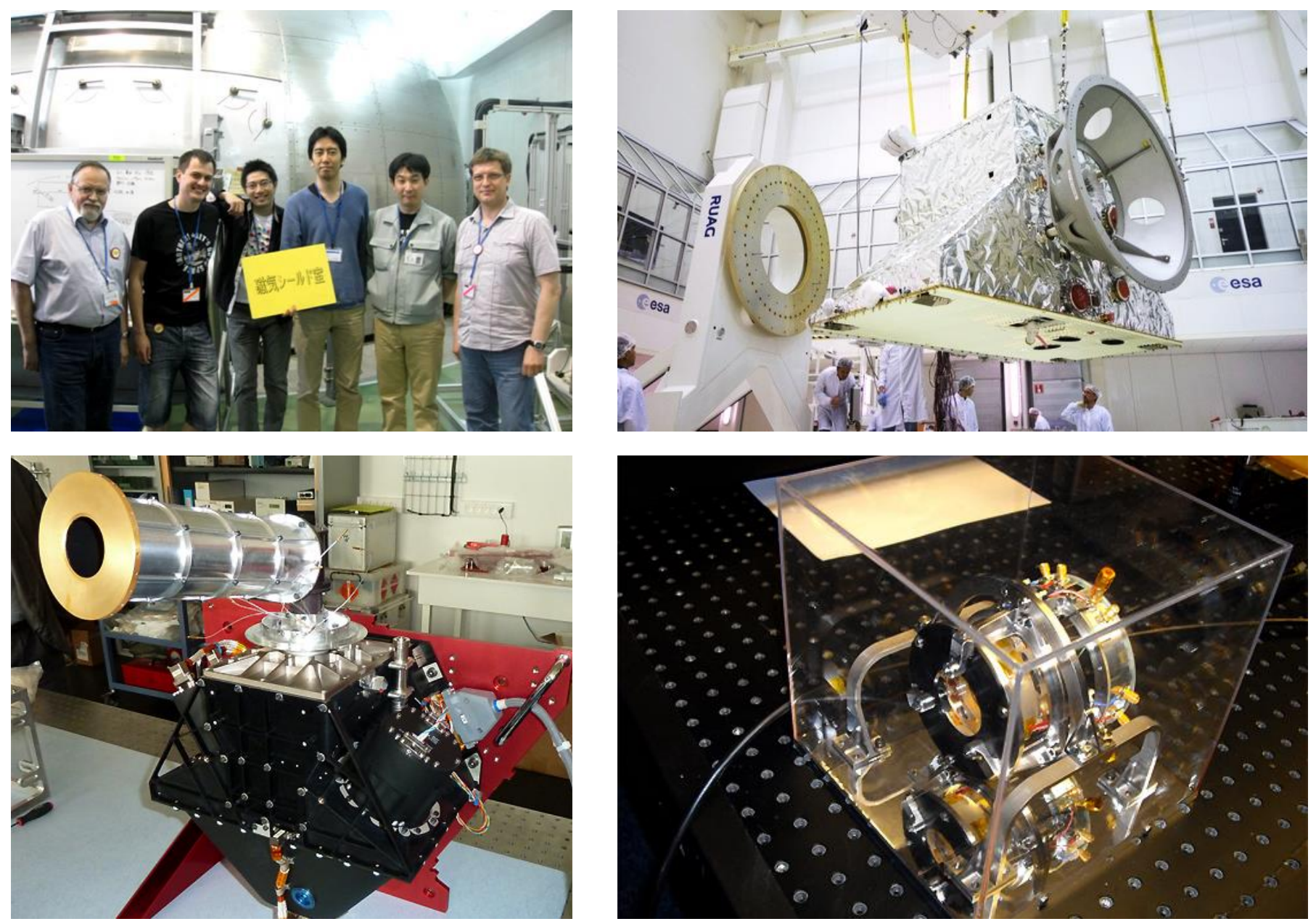


\section{Content}

- Mars missions (ExoMars 2016 and 2020)

- Mercury mission (BepiColombo)

- Lunar program

- Earth observations

- Telescopes for Astrophysics

- Example of the project beyond 2025 (Venera-D) 


\section{LUNAR PROGRAM}
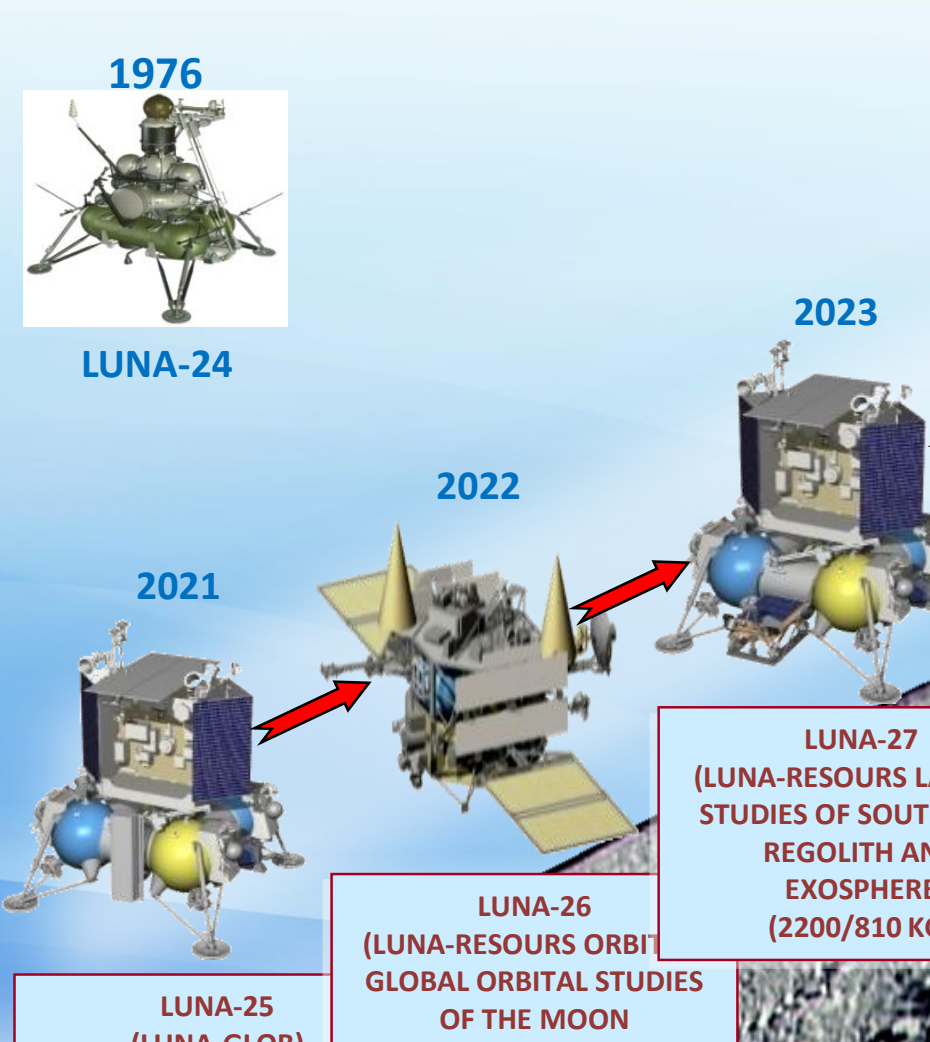

2022

(LUNA-GLOB)

$\sqrt{3}$

023

TECHNOLOGY OF POLAR

SOFT LANDING, STUDY OF

LUNAR SOUTH POLE

(1450/530 KG)

OF THE MOON

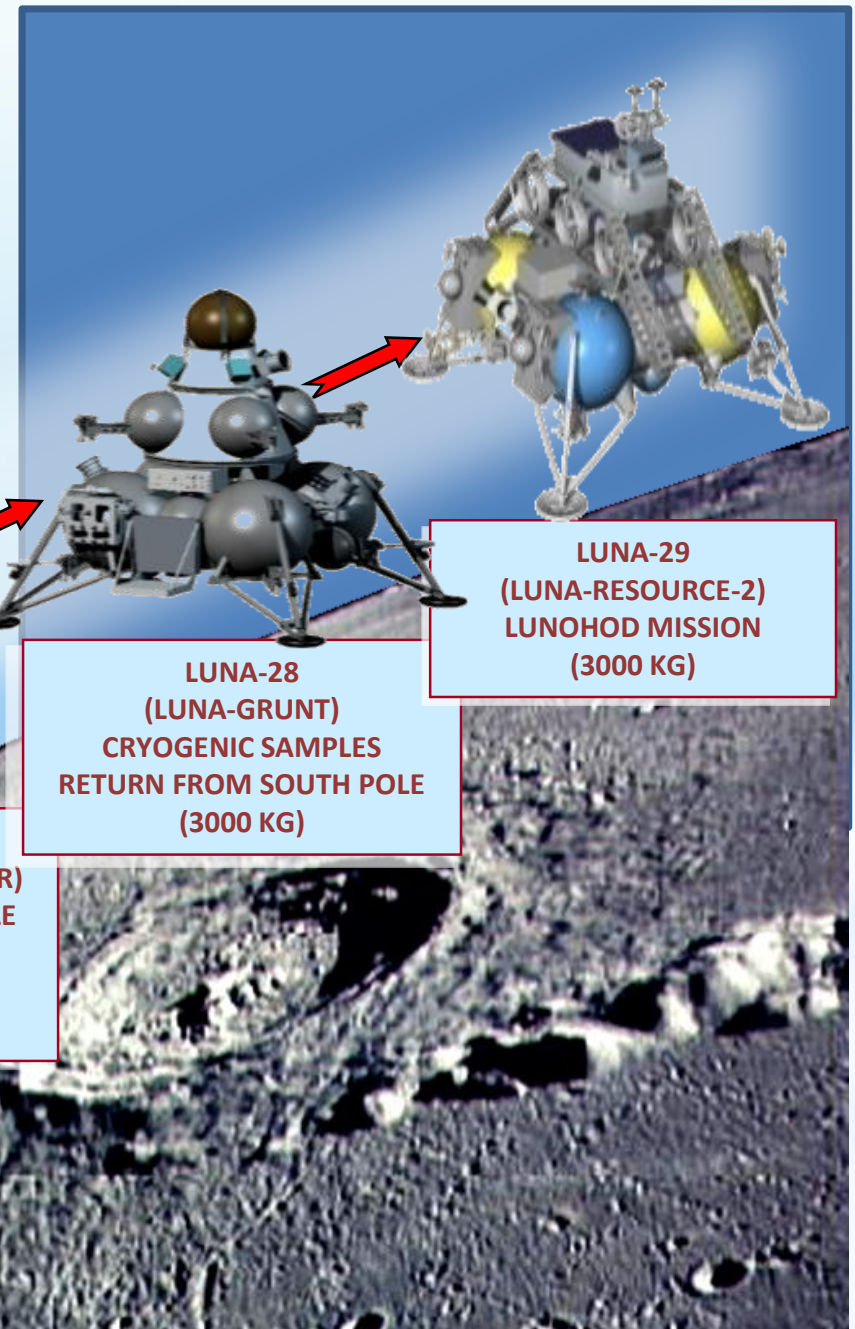

3. 


\section{Luna-25 LANDER $\quad 2019 \rightarrow 2021$}

\section{Luna-25 (Luna-Glob) polar landing demonstrator}

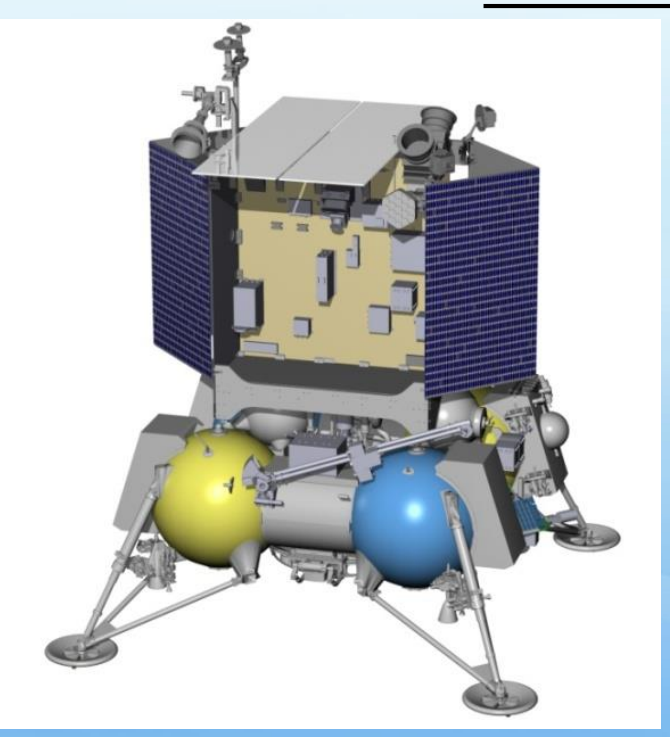

$\underline{\text { REGOLITH }}=$ LUNAR SOIL TILLAGED BY MICROMETEORITES AND SOLAR WIND

\section{Technology:}

- Re-design of soft landing technology

- Pole-Earth radio link tests and experience

- Thermal design validation

- Robotic arm testing and validation

\section{Science:}

1.Mechanical/thermal properties of polar regolith 2.IR composition measurements of polar regolith 3. Water content and elements abundance in the shallow subsurface of the polar regolith

4.Plasma and neutral exosphere at the pole

5.Dust exosphere at the pole

6.Thermal variations of the polar regolith
Optics:

Television cameras

(similar to TSPP for EM-2020)

IR-spectrometer 


\section{Luna-25 (Luna-Globe) and Luna-27 (Luna-Resource-1)}

LIS-TV-RPM - Lunar Infrared Spectrometer with TV cameras

LIS/Luna-25 was used a prototype for ISEM/ExoMars-2020. Now ISEM is used as a prototype for LIS/Luna-27

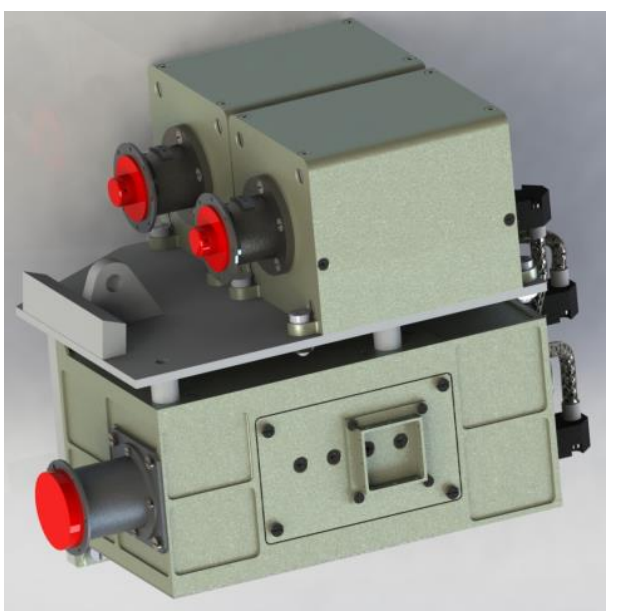

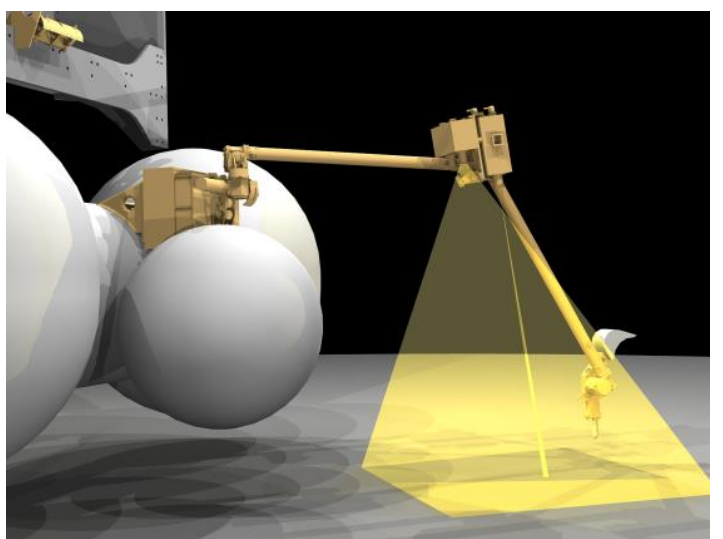

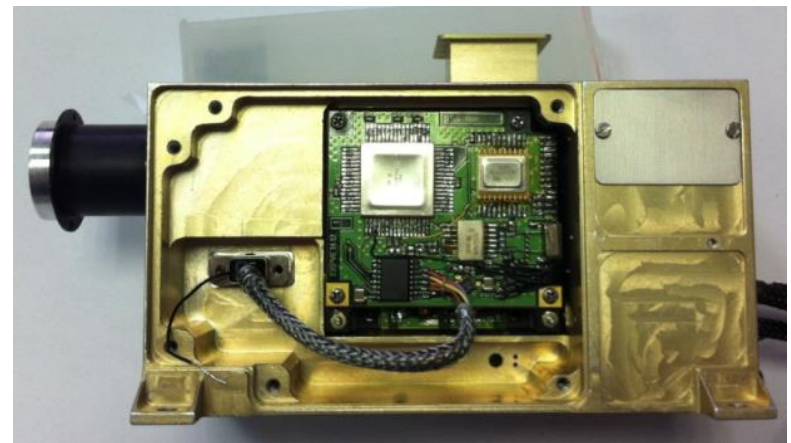




\section{Luna-26 ORBITER 2021-2022}

\section{Polar Orbiter Luna-26 (Luna-Resource)}

\section{Technology:}

-Polar-orbit UHF radio link tests and

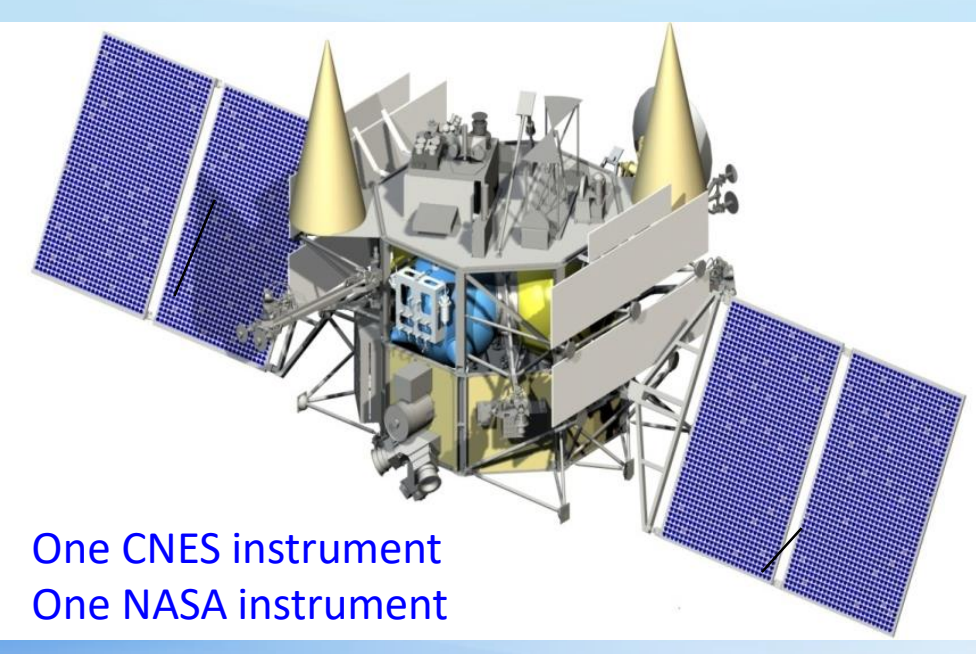

experience

- Orbital operations

\section{Science:}

- Space plasma in the lunar vicinity

- Lunar monitoring

- Luna-27 landing sites candidates 


\section{Luna-26 (Luna-Resource orbital)}

LEVUS - UV spectrometer, twin of Phebus/Bepi Colombo

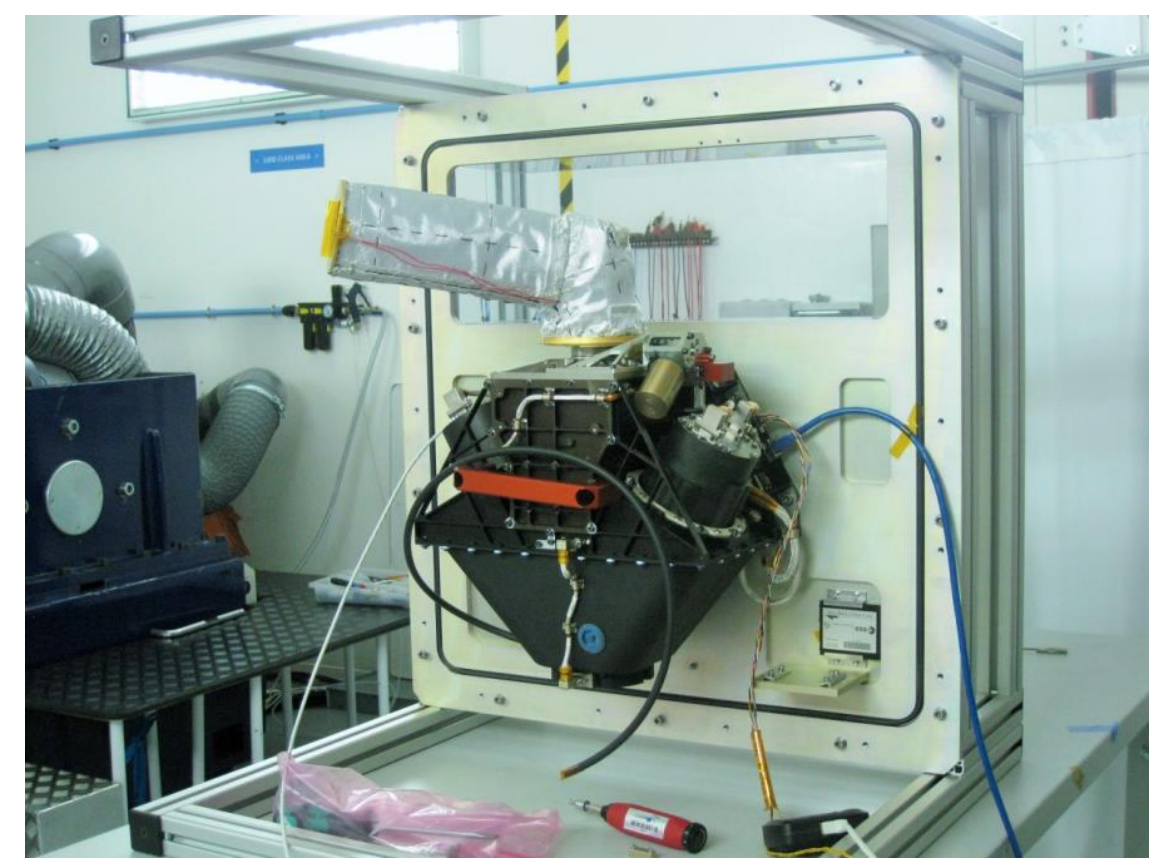




\section{LYMUS/Luna-26 - Lyman-alpha monitoring}

Prototype - MAVEN/IUVS the Imaging Ultraviolet Spectrograph

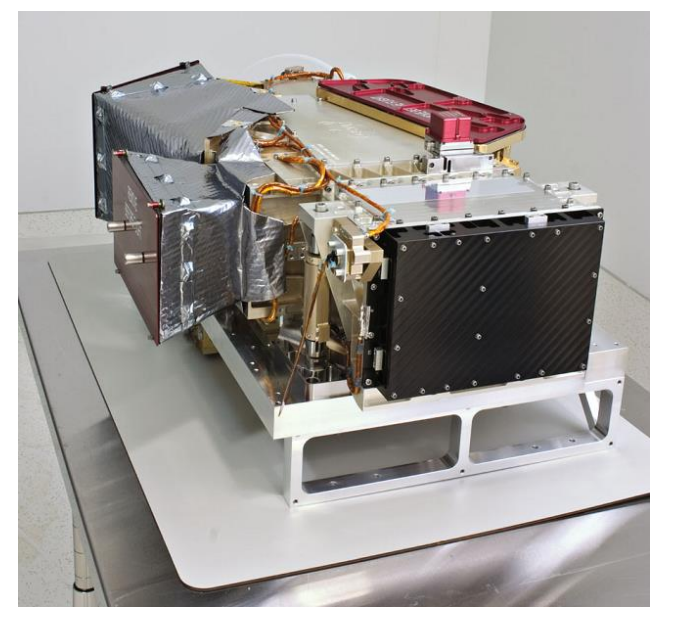

- high resolution echelle mode observations;

- spectral resolution at Lyman-a of 0.008 $\mathrm{nm}$, and a dispersion sampling of $0.00071 \mathrm{~nm} /$ pixel;

- Field of view $-0.06^{\circ} \times 1.7^{\circ}$

- Mass - $22.1 \mathrm{~kg}$

- Dimensions $-61.7 \times 54.1 \times 23.1 \mathrm{~cm}^{3}$
Heliospheric background of Backscattered Lymanalpha radiation in the heliosphere:

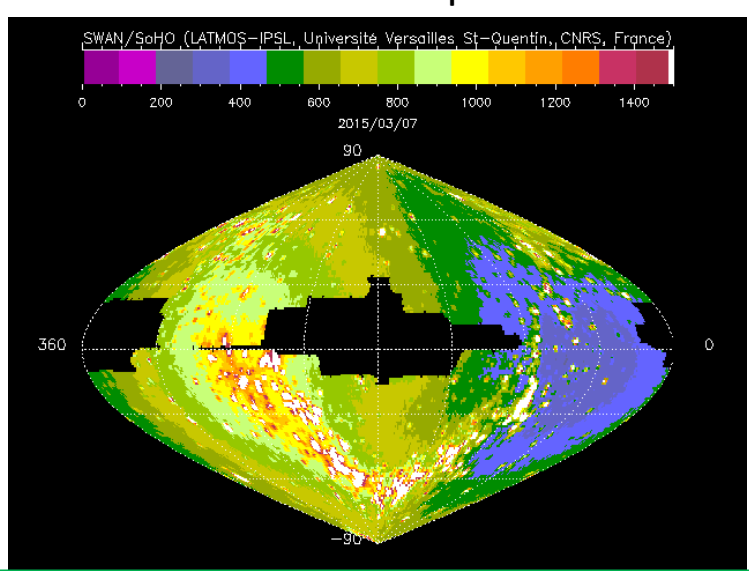

Scientific goals:

-Monitoring of heliolatitudinal dependence of the solar wind mass flux;

- Detection of active regions on the back side of the Sun for 2 week weather forecast;

- Global view on the Earth's geocorona from the Moon;

-Determination of 3D distribution of the interstellar hydrogen atoms inside the heliosphere;

- Comet discoveries and determination of their parameters; 


\section{Content}

- Mars missions (ExoMars 2016 and 2020)

- Mercury mission (BepiColombo)

- Lunar program

- Earth observations

- Telescopes for Astrophysics

- Example of the project beyond 2025 (Venera-D) 


\section{Mikhailo Lomonosov (satellite)}

One of instruments:

Tracking Ultraviolet Set Up system (TUS) measures fluorescence light radiated by EAS (Extensive Air Showers) of Ultra High Energy Cosmic Rays (UHECR) in the Earth atmosphere and detects transients in the UV-range

- Mirror $1.8 \mathrm{~m}^{2}$

- Detectors 256 of $15 \times 15 \mathrm{~mm}^{2}$ PMTs

- FOV $80 \times 80 \mathrm{~km}^{2}$

- Launched in April 2016

- strong UHECR candidate registered on October 3, 2016

- A variety of atmospheric events being registered 


\section{Near-Earth orbiters "Ionozond-2025"}

- In these program, a group of near-earth orbiters is to be launched for monitoring of Earth ionosphere and magnetosphere, solar activity and processes in terrestrial atmosphere including atmospheric ozone

- The orbital group will consist of 4 orbiters "Ionosphere", aimed mostly for observations of Earth, and 1 orbiter "Zond", aimed mostly for observations of Sun

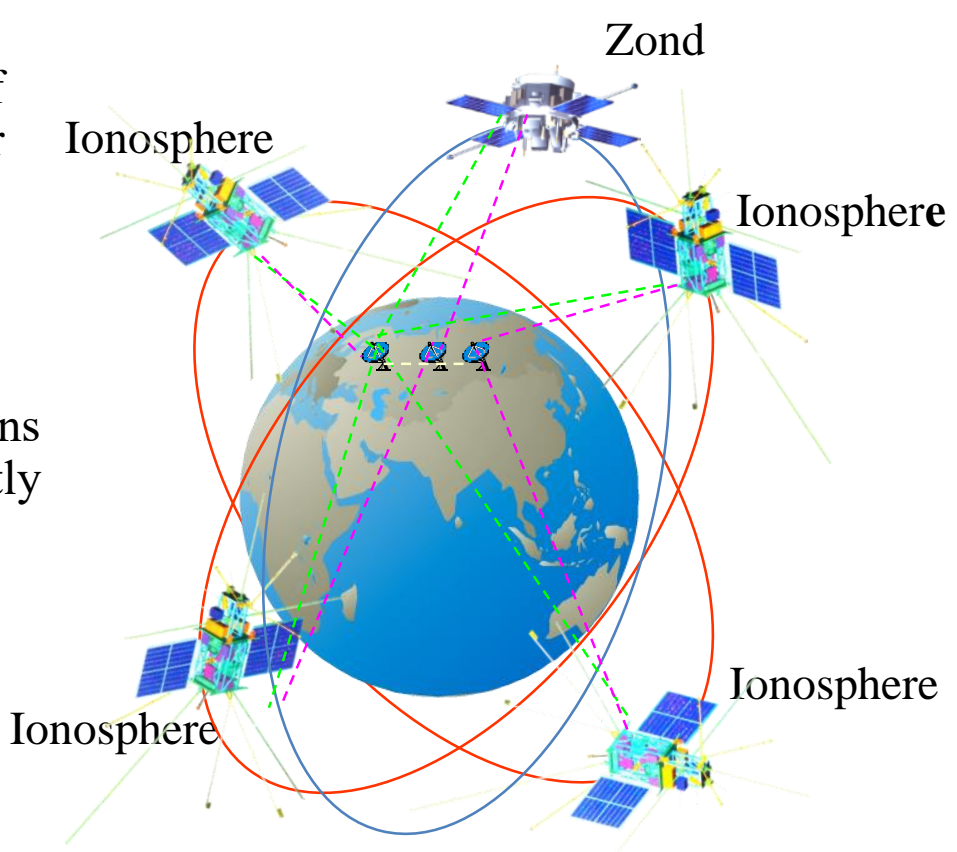


For each spacecraft "Ionosphere", a small UV-visible spectrometer "Ozonometer" is being developed
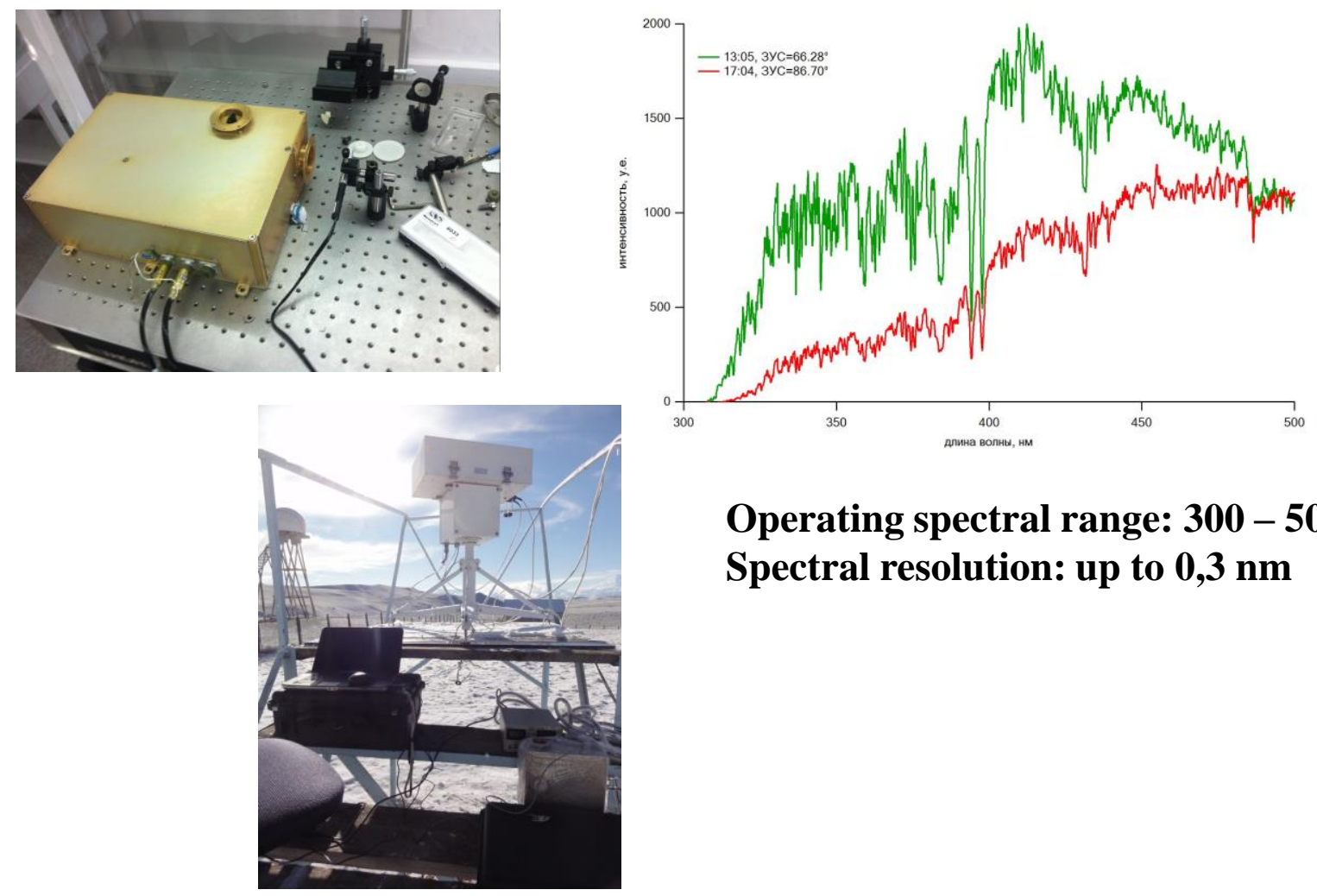

Operating spectral range: $300-500 \mathrm{~nm}$ Spectral resolution: up to $0,3 \mathrm{~nm}$ 
For spacecraft "Zond", the UV-visible imaging spectrometer

"Ozonometer" is being developed

Operating spectral range: $300-800 \mathrm{~nm}$

(Two channels: $300-400 \mathrm{~nm}$ and $400-800 \mathrm{~nm}$ )

Field of view: 100 degrees

Spatial resolution: 0,5 degree

Pixel size on Earth surface: $\approx 7 \times 7 \mathrm{~km}$

Spectral resolution: $0,3 \mathrm{~nm}$ in UV channel, $0,5 \mathrm{~nm}$ in VIS channel

Detector: $1024 \times 512$ pixels in UV channel, $2048 \times 512$ pixels in VIS channel
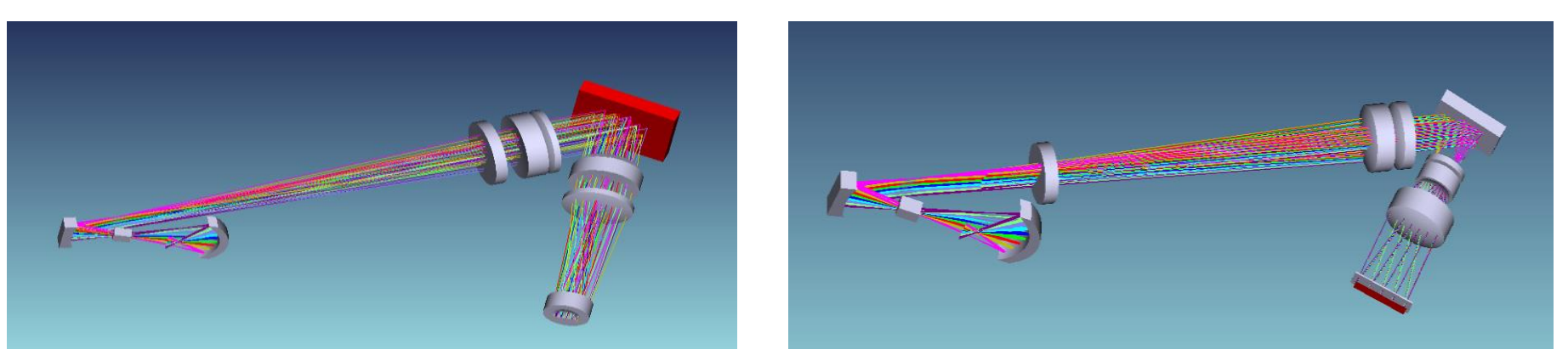


\section{Content}

- Mars missions (ExoMars 2016 and 2020)

- Mercury mission (BepiColombo)

- Lunar program

- Earth observations

- Telescopes for Astrophysics

- Example of the project beyond 2025 (Venera-D) 


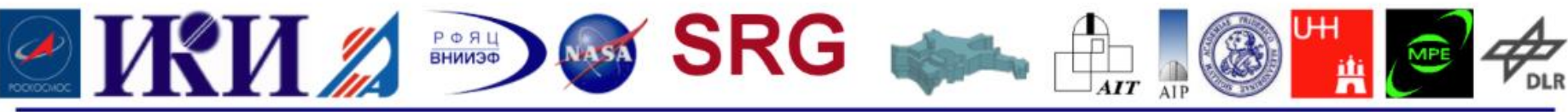

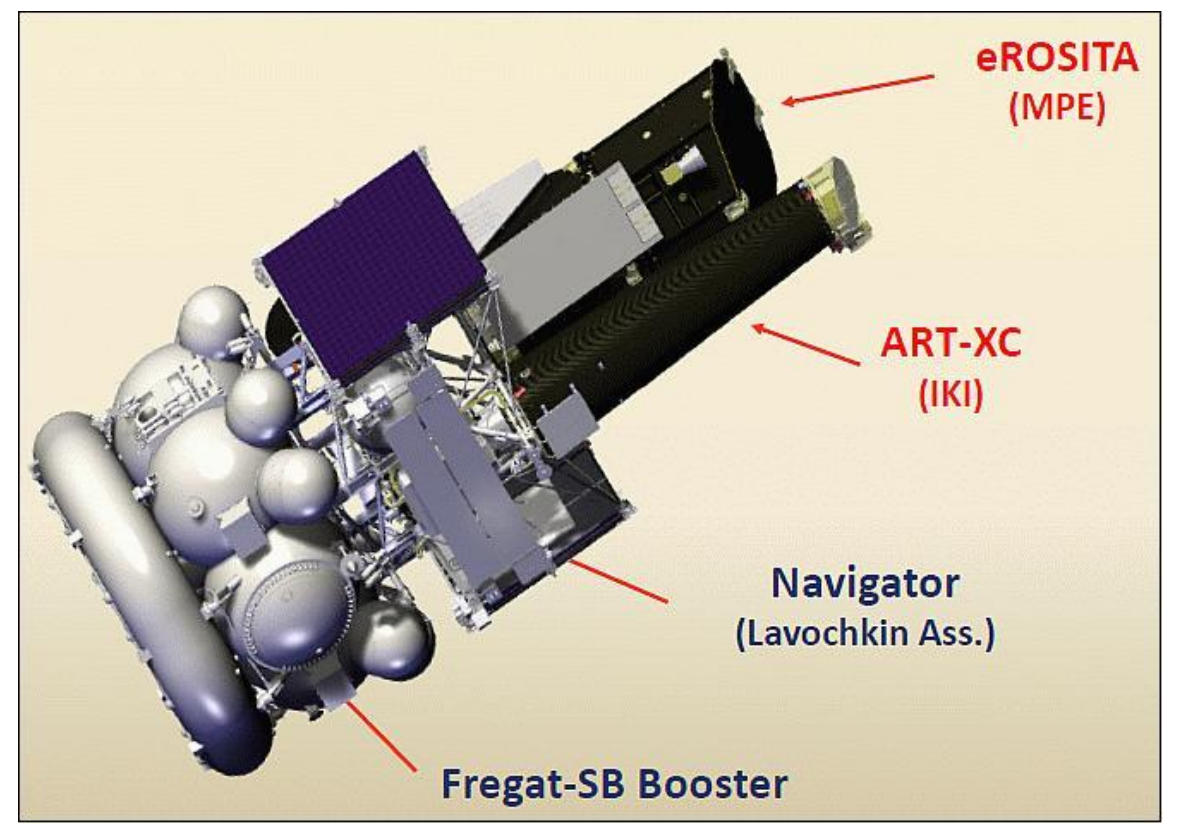

- Launch planned in 2019

- Science management: IKI RAS

- Spacecraft: Lavochkin Association

Transfer time to L2 point vicinity 70-80 days $\min / \max X(* 1000 \mathrm{~km})$ : $-200 / 400$ $\min / \max Y(* 1000 \mathrm{~km})$ : $-1100 / 1100$ $\min / \max Z(* 1000 \mathrm{~km})$ : $-400 / 400$

L2 Halo-orbit 



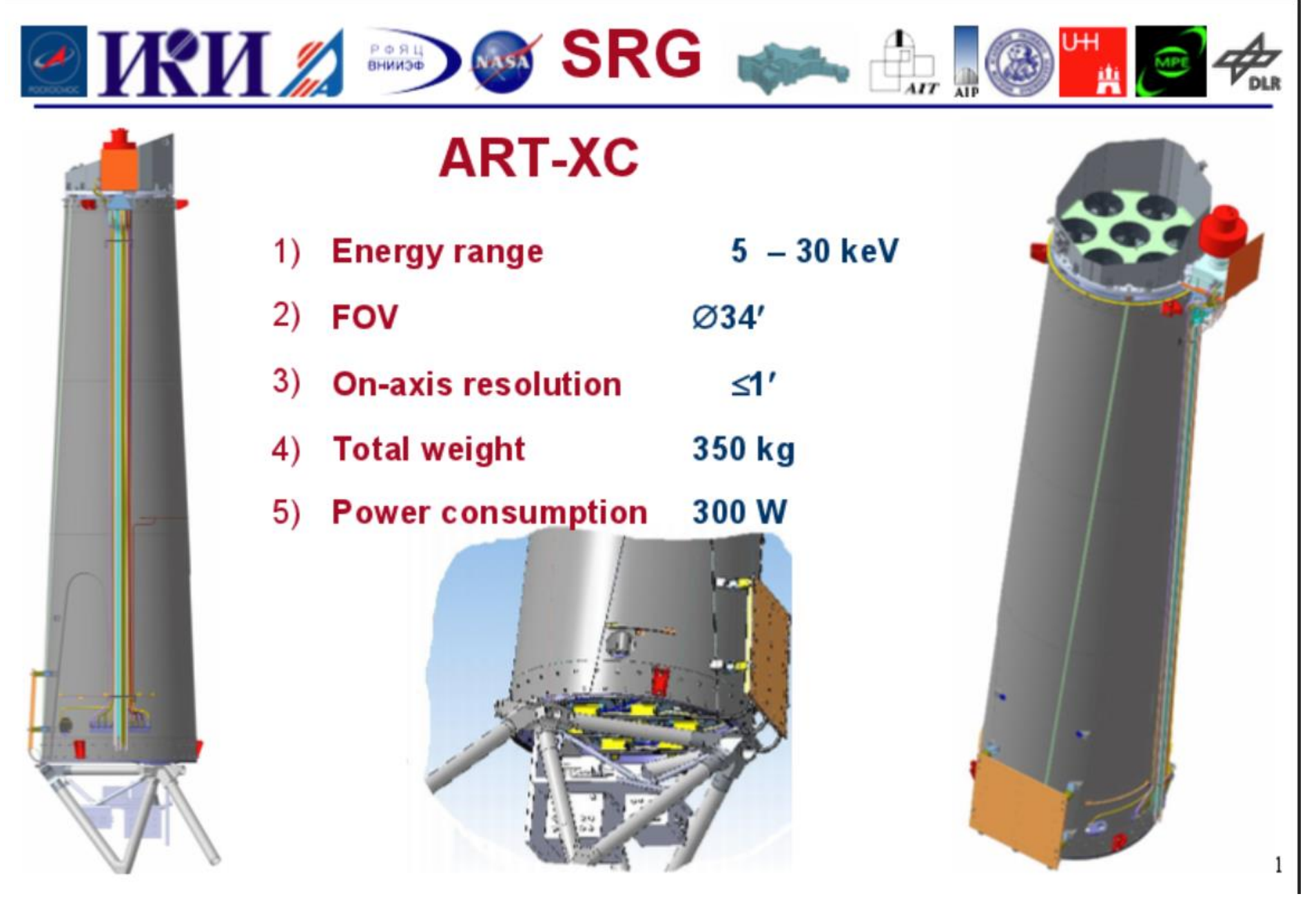




\section{WSO-UV mission concept}

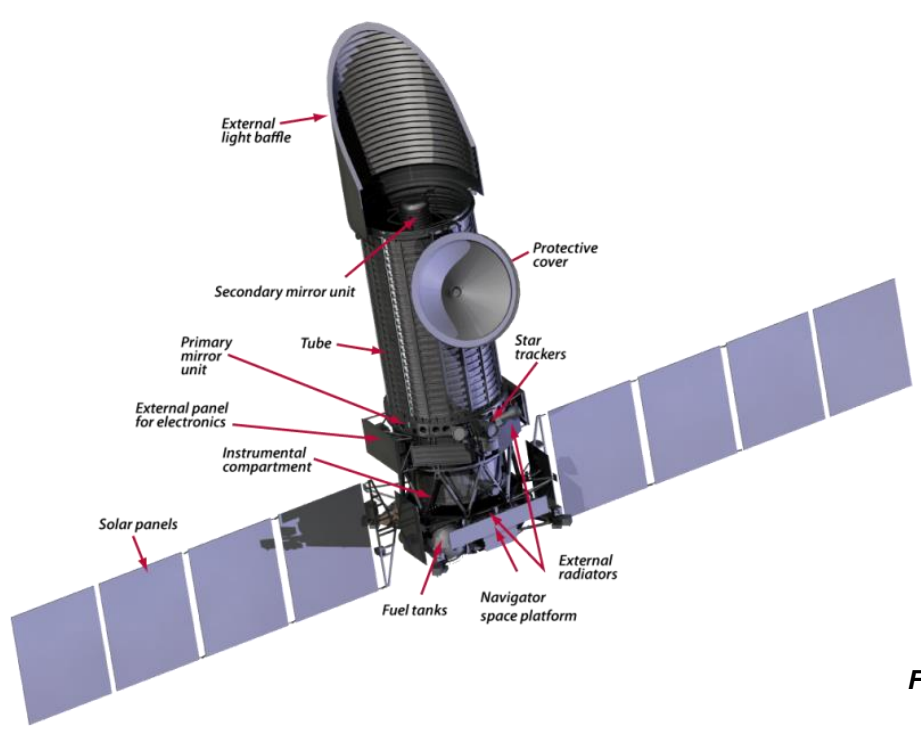

- Launch in 2023-24

- Orbit geosynchronous $14^{\circ}$

- Telescope \& Platform made in Russia.

- Pointing accuracy 0.1 " '

- Stabilization accuracy $0.1 "(3 \sigma)$

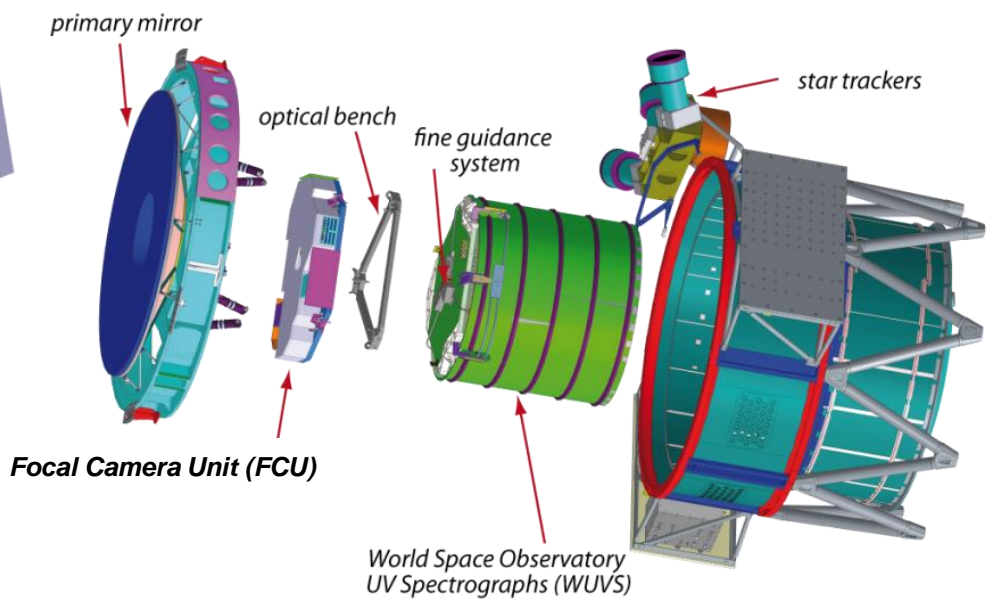

UV Spectrographs (WUVS) 


\section{T-170M telescope Spectrum UV of WSO-UV}

- Launch planned in 2024

- Science management: Institute of Astronomy, RAS (INASAN)

- Technical management: Lavochkin Association

- Spectrometers

- WUVS: R=50000 @ 115-310 nm, INASAN, VNIIEF Sarov (detectors from RAL\&e2v)

- ISSIS: R=1000, 0.5 arcsec Spain (?)

- Auxiliary electronics: IKI 
Three channels (spectrographs) of the WUVS :

Vacuum Ultraviolet Echele Spectrograph VUVES - 115-176 nm, R $\approx 50000$

Ultraviolet Echele Spectrograph UVES - 174-310 nm, R $\approx 50000$

Long Slit Spectrograph

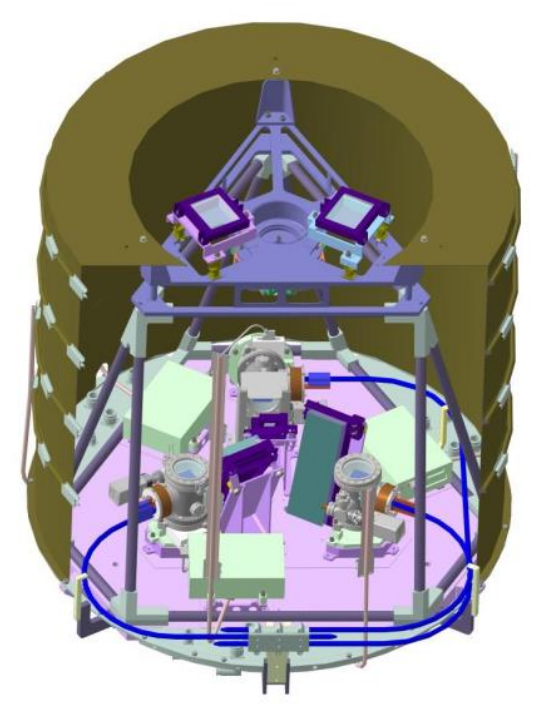

LSS - 115-305 nm, R=1000 
Two channels:

Far UV 115-175 HM (CsI MCP)

Near UV 185-310 HM (CsTe MCP)

Baseline for detectors is UVIT project

Field of view 70x75 arc.sec.

Angular resolution 0.1 arc.sec.

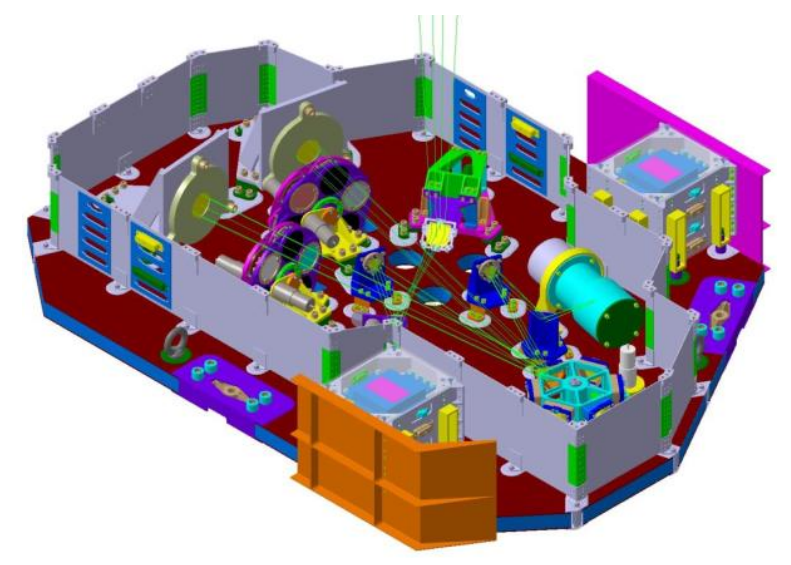

Slitless spectroscopy $(R>100)$

Initially designed in Spain, now to be built in Russia. MCP

detector supplied by Spain; two additional channels being considered (coronoghraph and slit spectrometer

(Russia+Japan) 


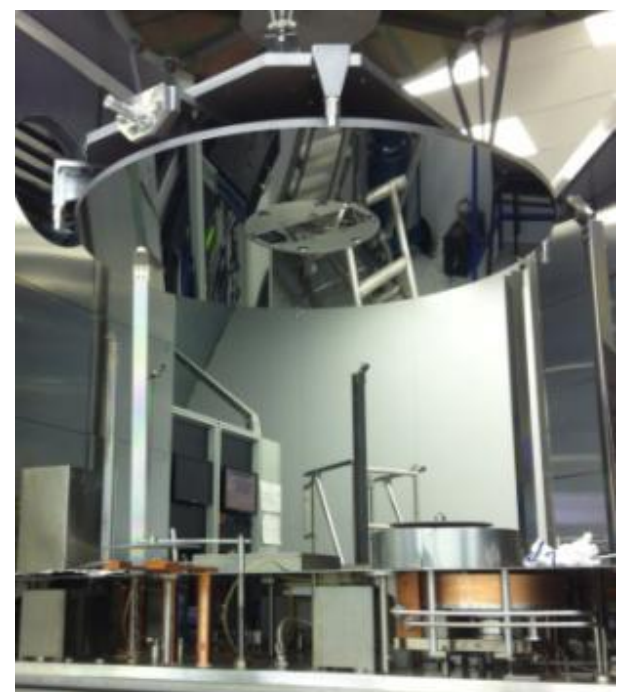

Primary mirror $\mathrm{Al}+\mathrm{MgF}_{2}$ coating (Denton vacuum camera)

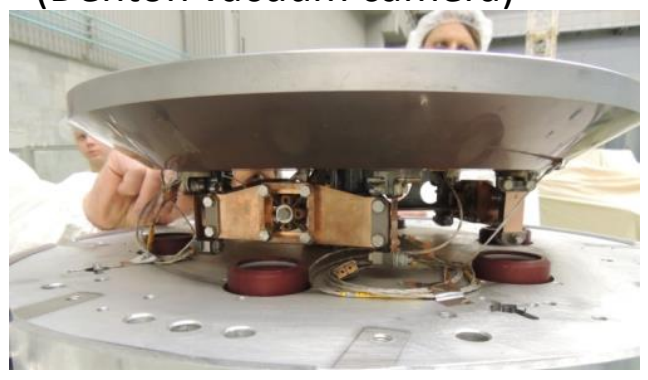

Secondary mirror

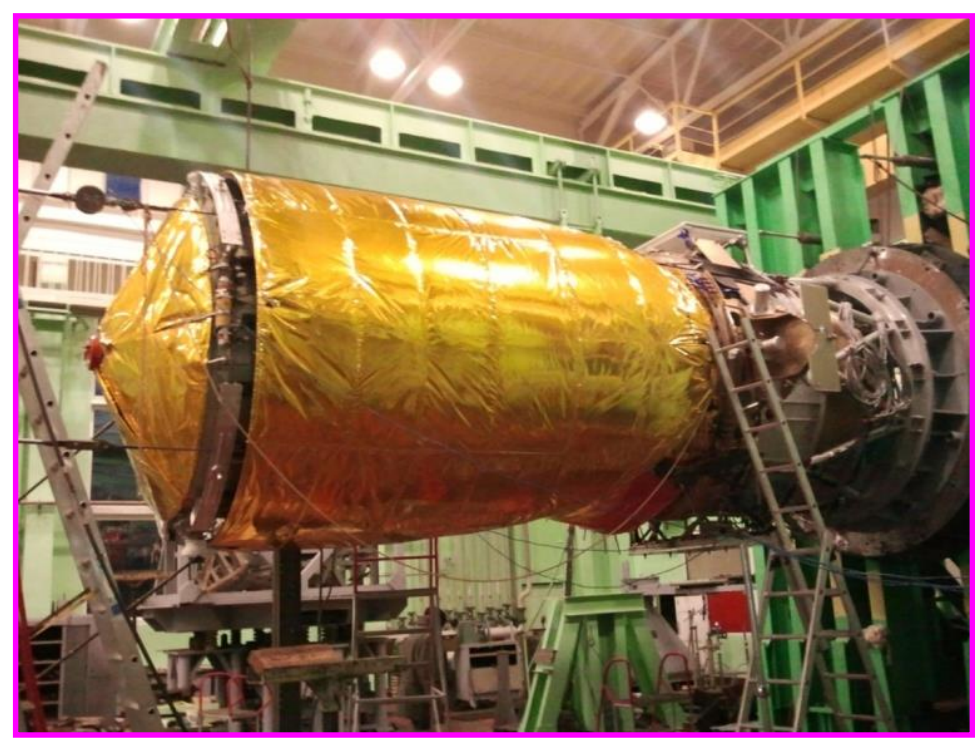

The telescope

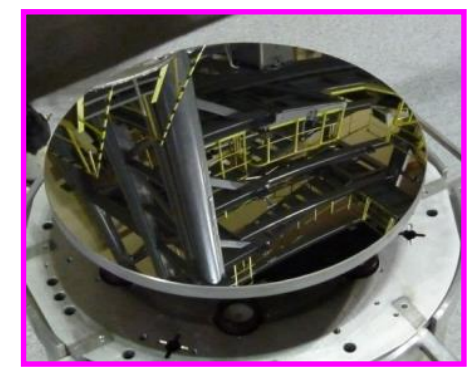




\section{ARKA}

\section{$2023 \div 2024$}

ARKA is a small explorer mission intended to get images of solar corona and transition layer of the Sun with the highest spatial resolution ever : $5 \mathrm{~km}$ per pixel. The Sun will be observed in narrow angle.
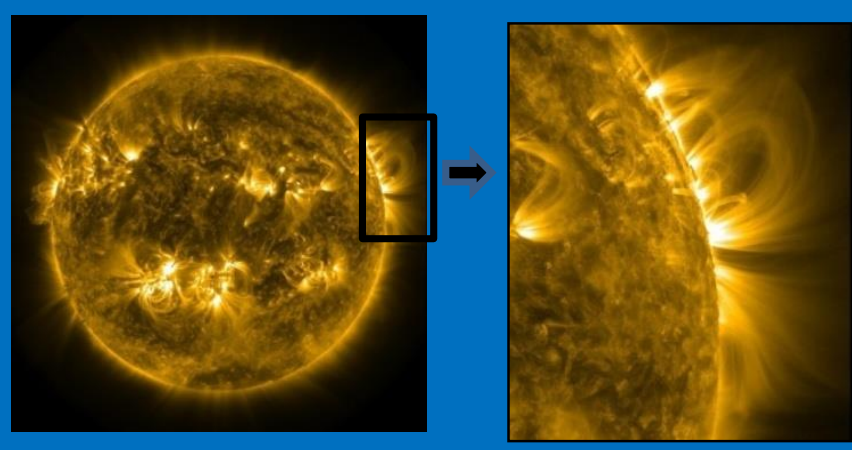

- Detectors are are $6 \mathrm{k} \times 6 \mathrm{k}$ CCDs by e2v

- Launch of Arka together with Resonance-MK demonstrator would allow to advance the project by one year.

Angular resolution is $\mathbf{0 . 1}$ " / pixel, which corresponds to $75 \mathrm{~km}$
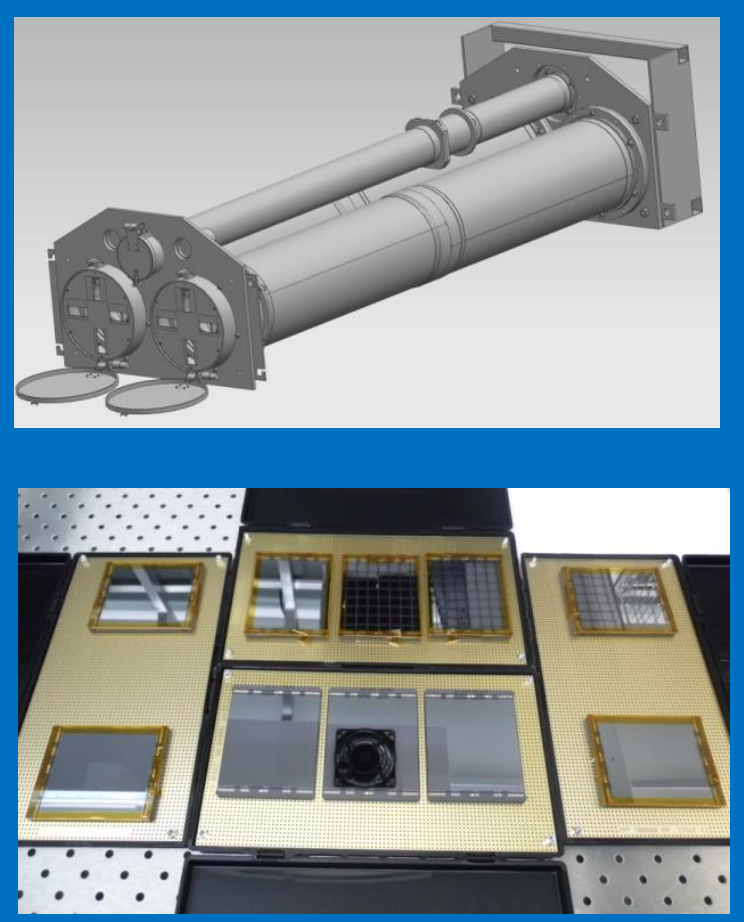


\section{Content}

- Mars missions (ExoMars 2016 and 2020)

- Mercury mission (BepiColombo)

- Lunar program

- Earth observations

- Telescopes for Astrophysics

- Example of the project beyond 2025 (Venera-D) 

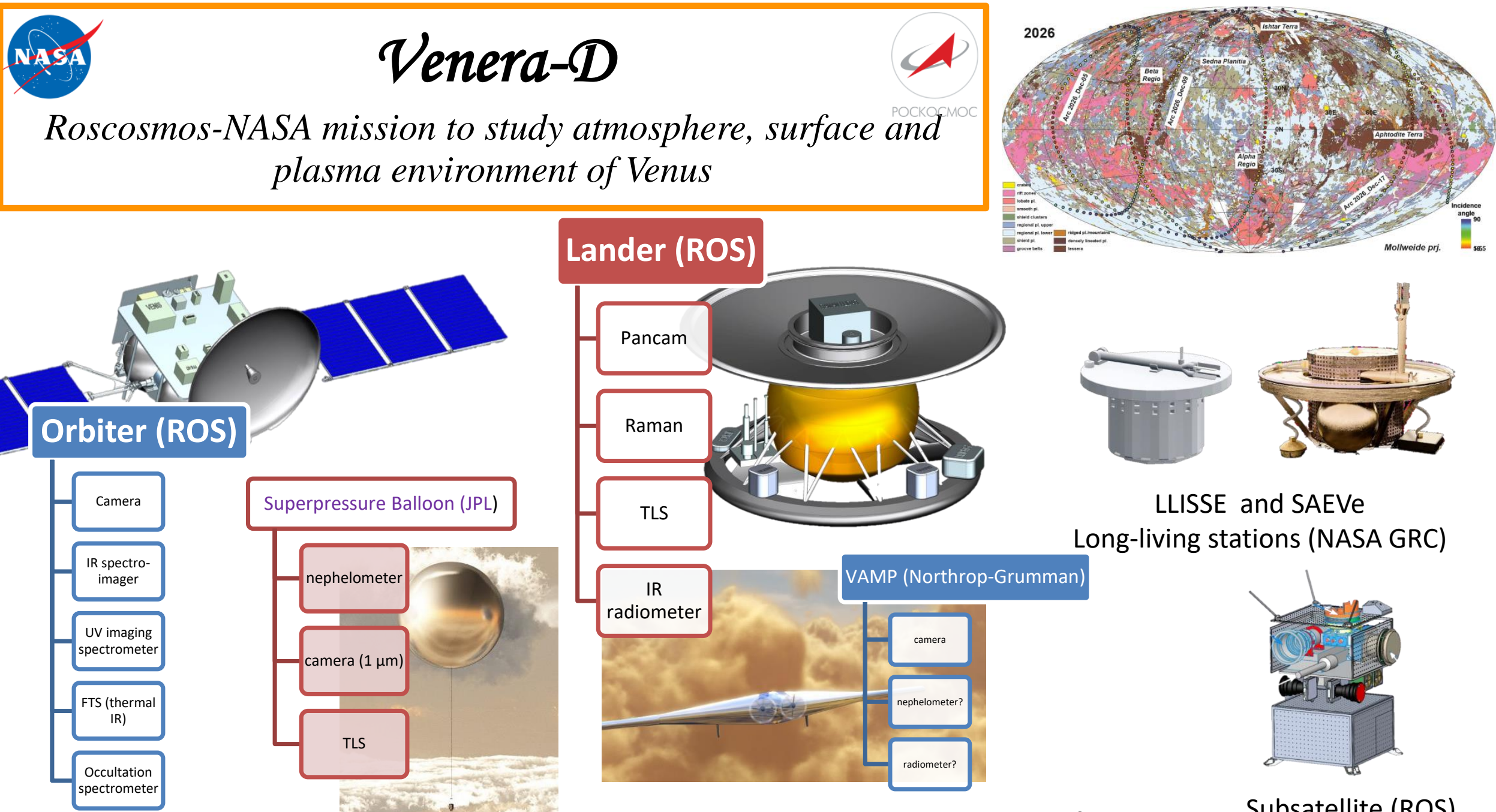

Venus Atmospheric Maneuverable Platform
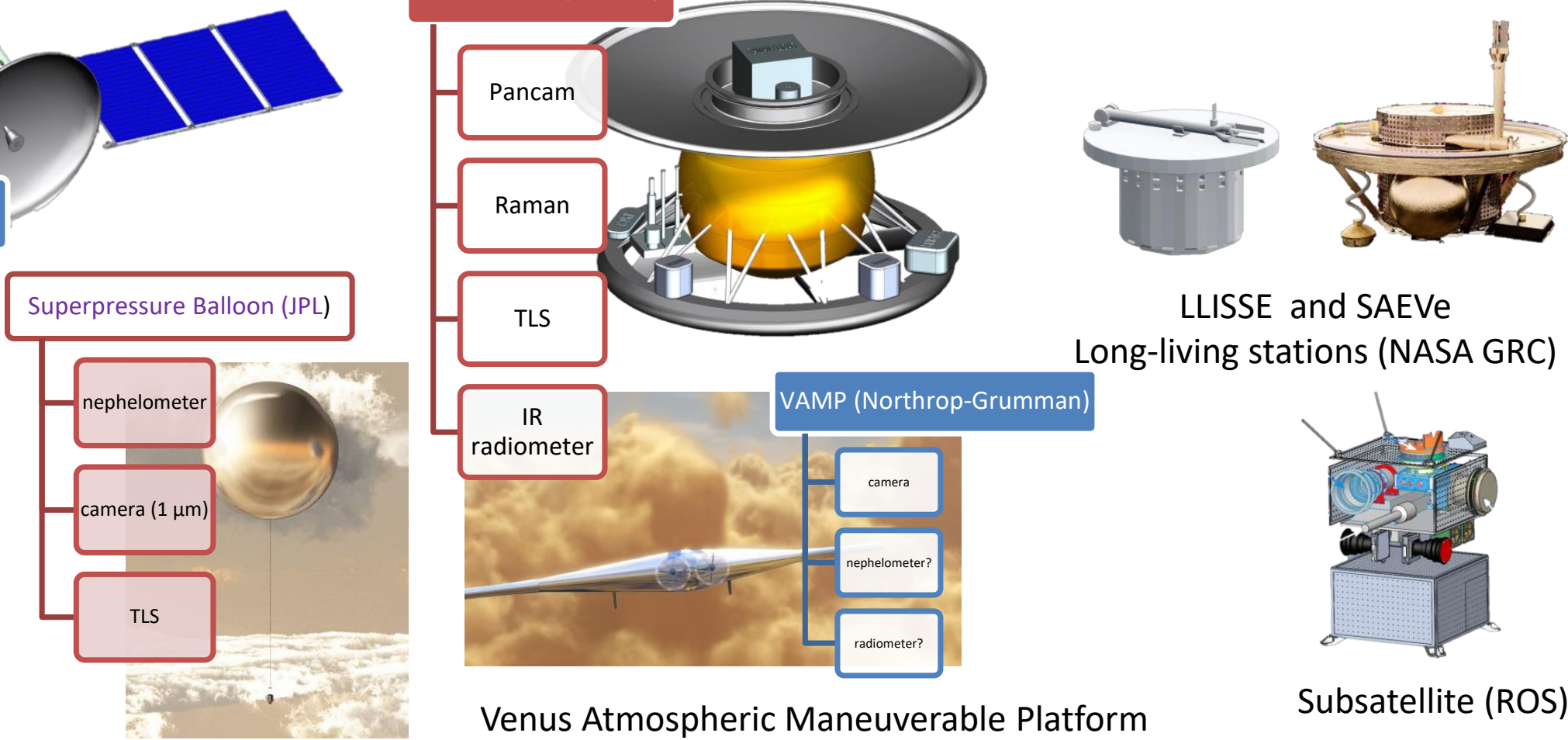

LLISSE and SAEVe

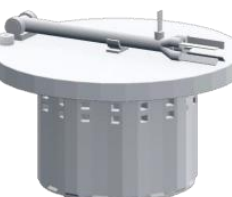
Long-living stations (NASA GRC)

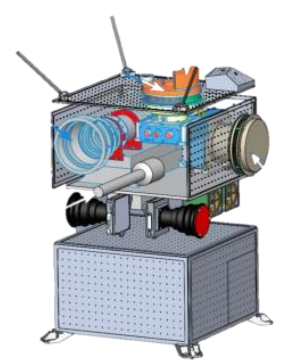

Subsatellite (ROS) 


\section{To conclude...}

- Optical instruments are core instruments of the majority of Russian space projects

- The role of spectral instruments has increased in recent and upcoming missions

- Since Mars-Express, acousto-optic spectrometers have become a "traditional Russian payload"

Prepared by

Oleg Korablev, IKI deputy director, head of Planetary Physics Department Yury Dobrolenskiy, IKI senior researcher

korab@iki.rssi.ru

dobrolenskiy@iki.rssi.ru 


\section{Federal Space Programme, Fundamental Space Research 2016-2025}

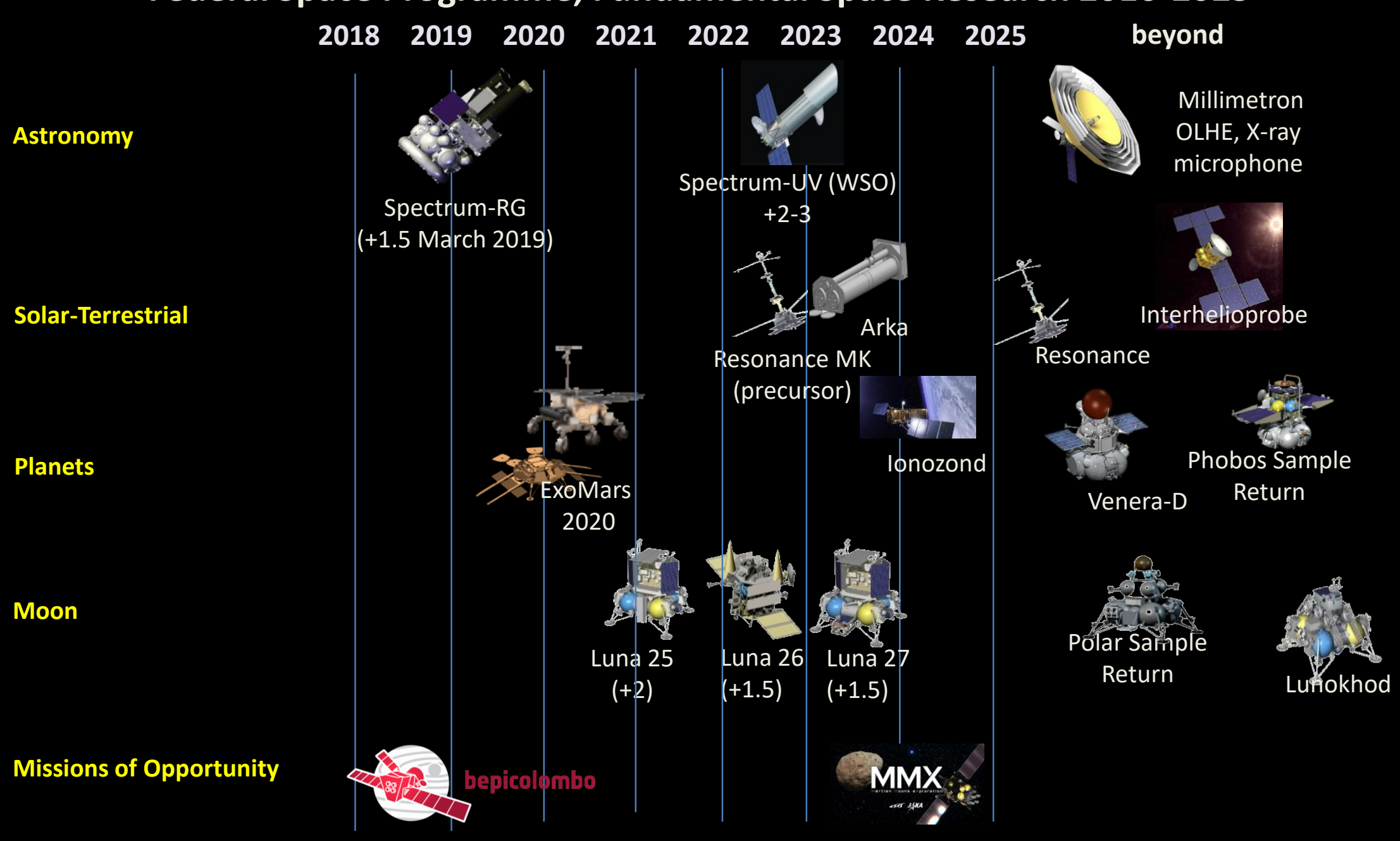

